\title{
Monitoring Asynchrony During Invasive Mechanical Ventilation
}

\author{
José Aquino Esperanza, Leonardo Sarlabous, Candelaria de Haro, Rudys Magrans, \\ Josefina Lopez-Aguilar, and Lluis Blanch
}

\author{
Introduction \\ Insufficient Assistance: Patients With High Respiratory Drive \\ Flow Starvation \\ Short-Cycling: Double-Triggering and Breath-Stacking \\ Overassistance: Patients With Low Respiratory Drive \\ Ineffective Efforts \\ Delayed or Prolonged Cycling \\ Reverse-Triggering: Entrainment Phenomenon \\ Assessment of Asynchronies \\ Asynchronies and Sleep in Critically Ill Patients \\ Management \\ Outcomes \\ Future Directions
}

\begin{abstract}
Mechanical ventilation in critically ill patients must effectively unload inspiratory muscles and provide safe ventilation (ie, enhancing gas exchange, protect the lungs and the diaphragm). To do that, the ventilator should be in synchrony with patient's respiratory rhythm. The complexity of such interplay leads to several concerning issues that clinicians should be able to recognize. Asynchrony between the patient and the ventilator may induce several deleterious effects that require a proper physiological understanding to recognize and manage them. Different tools have been developed and proposed beyond the careful analysis of the ventilator waveforms to help clinicians in the decision-making process. Moreover, appropriate handling of asynchrony requires clinical skills, physiological knowledge, and suitable medication management. New technologies and devices are changing our daily practice, from automated real-time recognition of asynchronies and their distribution during mechanical ventilation, to smart alarms and artificial intelligence algorithms based on physiological big data and personalized medicine. Our goal as clinicians is to provide care of patients based on the most accurate and current knowledge, and to incorporate new technological methods to facilitate and improve the care of the critically ill. Key words: asynchrony; mechanical ventilation; patient-ventilator interactions; respiratory monitoring; respiratory physiology. [Respir Care 2020;65(6):847-869. (C) 2020 Daedalus Enterprises]
\end{abstract}

Drs Aquino Esperanza, Sarlabous, de Haro, Lopez-Aguilar, and Blanch are affiliated with the Critical Care Center, Hospital Universitari Parc Taulí, Institut d' Investigació i Innovació Parc Taulí, Sabadell, Spain. Drs Aquino Esperanza, de Haro, Lopez-Aguilar, and Blanch are affiliated with the Centro de Investigaciones Biomedicas en Red Enfermedades Respiratorios, Instituto de Salúd Carlos III, Madrid, Spain. Dr Aquino Esperanza is affiliated with the Facultat de Medicina, Universitat de Barcelona, Barcelona, Spain. Dr Sarlabous is affiliated with the Centro de Investigaciones Biomedicas en Red Bioingenieria, Biomateriales y Nanotecnologia, Insituto de Salúd Carlos III, Madrid,
Spain. Dr Magrans is affiliated with the Bettercare SL, Sabadell, Spain. Drs de Haro and Blanch are affiliated with the Universitat Autònoma de Barcelona, Bellaterra, Spain.

A version of this paper at the ResPiRAtory CARE Journal Conference, held June 10-11, 2019, in St. Petersburg, Florida.

Dr Blanch is the inventor of a patent owned by the Corporació Sanitària Parc Taulí (US Patent 12/538,940). Dr Blanch has disclosed a relationship with BetterCare SL. This work was supported by the Plan 


\section{Monitoring Asynchrony During InVasive Mechanical Ventilation}

\section{Introduction}

The complexity of control of breathing involves feedback from chemoreceptors (central and peripheral), mechanoreceptors, and vagal inputs from the lung, chest wall, and respiratory muscles. ${ }^{1,2}$ During mechanical ventilation, the ventilator must work in synchrony with the patient's respiratory rhythm to unload inspiratory muscles effectively and safely. Clinicians must be aware of various issues related to the complexity of patient-ventilator interactions and be able to recognize abnormal interactions. ${ }^{3}$

Patient-ventilator asynchronies are common, occurring throughout the duration of mechanical ventilation and in seemingly apneic patients. ${ }^{4}$ Asynchronies can result in dyspnea, anxiety, delirium, cognitive alterations, and selfinflicted lung injury; they could also induce vigorous inspiratory efforts leading to high stress (ie, elevated transpulmonary pressure), strain (ie, global or regional lung overdistention), and consequent diaphragm and lung injury. Asynchronies are also associated with longer duration of mechanical ventilation. ${ }^{1,5-8}$

The traditional classification of asynchronies on the basis of the phase of the respiratory cycle in which they occur (eg, inspiratory in the pressurization phase, cycling-off in the expiratory phase, and expiratory phase) does not correspond well with the clinical and pathophysiological mechanisms involved. It is important to remember two things. First, a given asynchrony could reflect different clinical conditions (eg, double-triggering could arise from flow asynchrony, high respiratory drive, reverse-triggering, or even partial endotracheal tube dislocation or a cuff leak). ${ }^{9-12}$ Second, a given pathophysiological mechanism could result in different asynchronies depending on the ventilator mode; for example, high respiratory drive could cause double-triggering and breath-stacking during volume-control continuous mandatory ventilation (VC-CMV), but, depending on the preset inspiratory and expiratory triggers, it could cause ineffective efforts or short-cycling during pressure support ventilation (PSV).

It has been suggested recently that focusing on the conditions leading to patient-ventilator mismatch could help in understanding the underlying mechanisms and in designing treatment strategies. ${ }^{6,13} \mathrm{We}$ will focus mainly on classification based on the appropriateness

Nacional de R+D+I, ISCIII Subdirección General de Evaluación y el Fondo Europeo de Desarrollo Regional, and CIBER Enfermedades Respiratorias and Fundació Parc Taulí.

Correspondence: Lluis Blanch MD PhD, Critical Care Center, Parc Taulî Hospital Universitari, Institut d'Investigació i, Innovació Parc Taulí I3PT, Universitat Autònoma de Barcelona, Parc Taulí 1, 08208 Sabadell, Spain.E-mail:1blanch@tauli.cat.

DOI: $10.4187 /$ respcare.07404 of the level of ventilator assistance, and we will discuss other phenomena, such as reverse-triggering, separately.

\section{Insufficient Assistance: Patients With High Respiratory Drive}

\section{Flow Starvation}

Spontaneous breathing during mechanical ventilation can be beneficial or deleterious, depending on the strength of the inspiratory effort and the severity of lung injury. ${ }^{14-16}$ As patients recover, their need for ventilatory support varies: they demand a transition from more ventilator-controlled support to a support in which their spontaneous efforts trigger the ventilator, progressing to partial support and, eventually, to weaning; throughout this process, ventilation must be tailored to the individual to avoid excessive inspiratory efforts that can cause or aggravate lung or diaphragm injury (Fig. 1, Fig. 2, Fig. 3). ${ }^{17-20}$ In patients with lung injury, gentle spontaneous effort improves gas exchange and aeration. However, vigorous inspiratory effort leading to huge increases in transpulmonary pressure can cause double-triggering and associated breath-stacking, resulting in lung injury due to increased lung stress and strain and to increased lung perfusion caused by augmented vascular distending pressures. Evidence, mostly from patients with ARDS, indicates that preventing injurious spontaneous efforts through neuromuscular blockade ${ }^{21,22}$ or high PEEP $^{23}$ results in greater physiological levels of tidal volume $\left(\mathrm{V}_{\mathrm{T}}\right)$ and transpulmonary pressure, respectively.

In patients with acute respiratory failure, even those receiving mechanical ventilation, altered gas exchange, high metabolic demands, or stimuli from mechanoreceptors and vagal inputs can cause high respiratory drive. ${ }^{5}$ In this clinical scenario, mechanical ventilation must be tailored to ensure appropriate inspiratory flow (usually 50 $70 \mathrm{~L} / \mathrm{min}$ ), inspiratory time, and $\mathrm{V}_{\mathrm{T}}$. Inspiratory-flow mismatch occurs when the ventilator fails to meet the patient's flow demand, usually because flow delivery is set inappropriately low or because the combination of $\mathrm{V}_{\mathrm{T}}$ and inspiratory time fails to provide adequate air flow. ${ }^{10,24,25}$ Inspiratory-flow mismatch is more common in modes where flow is unmodifiable, such as VC-CMV with constant flow. ${ }^{26}$ Inspiratory-flow mismatch could be corrected by increasing ventilator flow delivery or by using the variable flow pressure-limited breath. In a seminal study, Ward et $\mathrm{al}^{27}$ reported that substantial inspiratory muscle activity can occur during mechanical ventilation, particularly during assisted mechanical ventilation at low trigger sensitivity and flow. In this condition, inspiratory work of breathing accounted for nearly $65 \%$ of the total inspiratory work. Other authors have noted the importance of titrating the peak inspiratory flow to patients' 

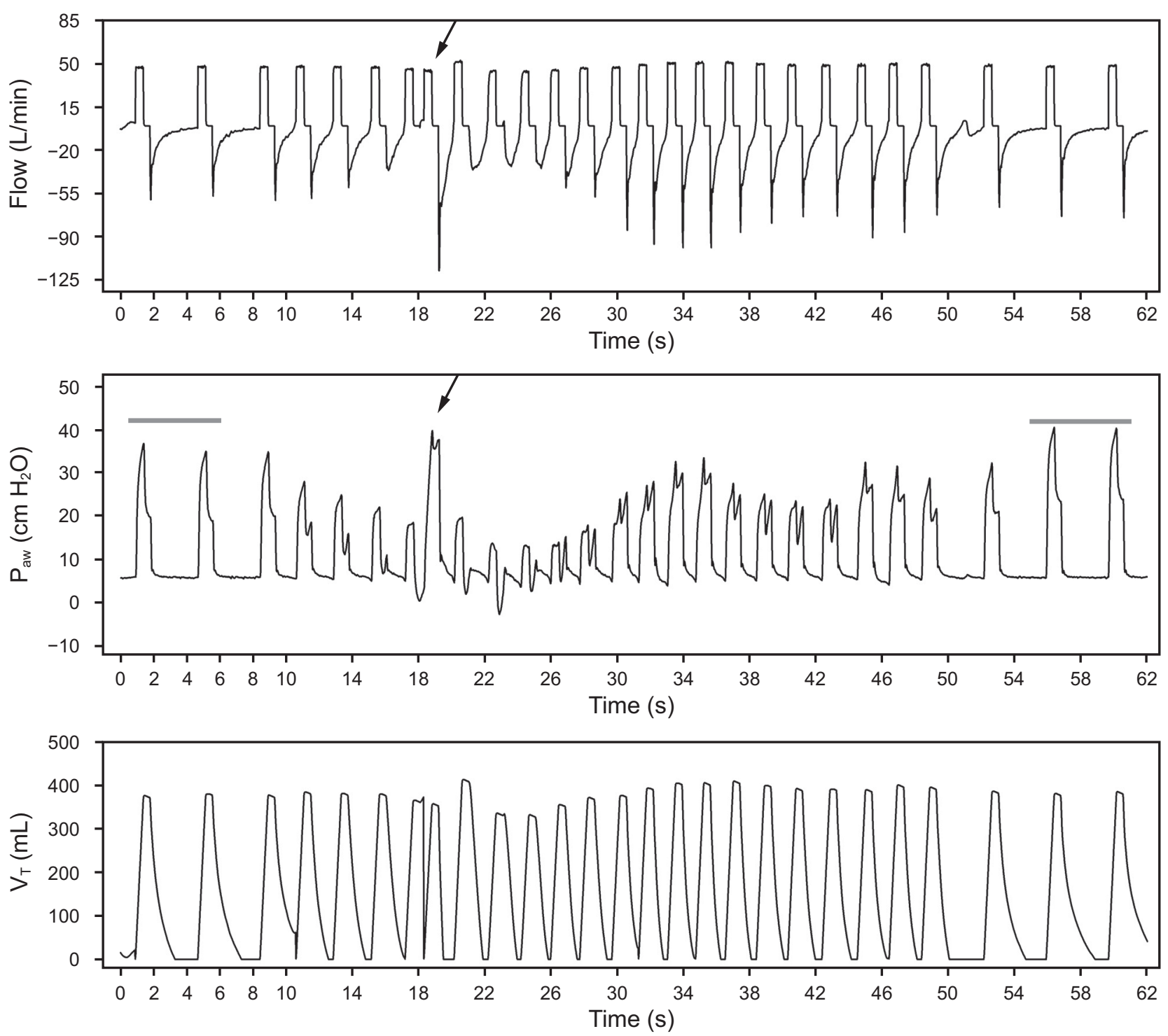

Fig. 1. Flow starvation seen on tracings of air flow, airway pressure $\left(P_{a w}\right)$, and tidal volume $\left(V_{T}\right)$ in a mechanically ventilated patient on volumecontrol continuous mandatory ventilation. Flow starvation (ie, inspiratory flow mismatching) occurs when the ventilator fails to meet the patient's flow demand. In this case, ventilator air flow is set inappropriately low at $40 \mathrm{~L} / \mathrm{min}$. Inspiratory effort begins after a period of synchrony (line) during mechanical inflation manifested by a progressive decrease in $\mathrm{P}_{\mathrm{aw}}$, along with shortening of the expiratory time and breath-stacking (arrow). Notice a progressive return to synchrony (line).

needs relative to respiratory center activity. Cinnella et $\mathrm{al}^{28}$ compared the effects on the respiratory work rate of assisted ventilation, delivered either with a square or decelerating flow pattern in VC-CMV versus with a constant pressure in pressure-control CMV (PC-CMV). At high $\mathrm{V}_{\mathrm{T}}$, no difference between VC-CMV and PC-CMV was observed, suggesting that the effect of air flow is less relevant. However, at moderate $\mathrm{V}_{\mathrm{T}}$, lower peak flow in VCCMV failed to meet patients' demands, resulting in greater work of breathing than in PC-CMV. Interestingly, when moderate $\mathrm{V}_{\mathrm{T}}$ and high inspiratory flow were applied, no significant differences were found between modes.
MacIntyre et $\mathrm{al}^{29}$ also reported that the variable flow pressure-limited breath was a better approach for matching vigorous patient efforts than adjusting a set flow on a conventional volume-cycled breath. Importantly, increasing inspiratory flow at similar $\mathrm{V}_{\mathrm{T}}$ implies a decrease in inspiratory time.

Dyspnea or air hunger is the sensation of breathing discomfort. ${ }^{30-33}$ Persistent inspiratory-flow mismatch can be associated with dyspnea, even when no respiratory signs are evident. Schmidt et $\mathrm{al}^{34}$ reported that half of intubated or tracheotomized patients on mechanical ventilation for $>24 \mathrm{~h}$ experienced dyspnea, and 

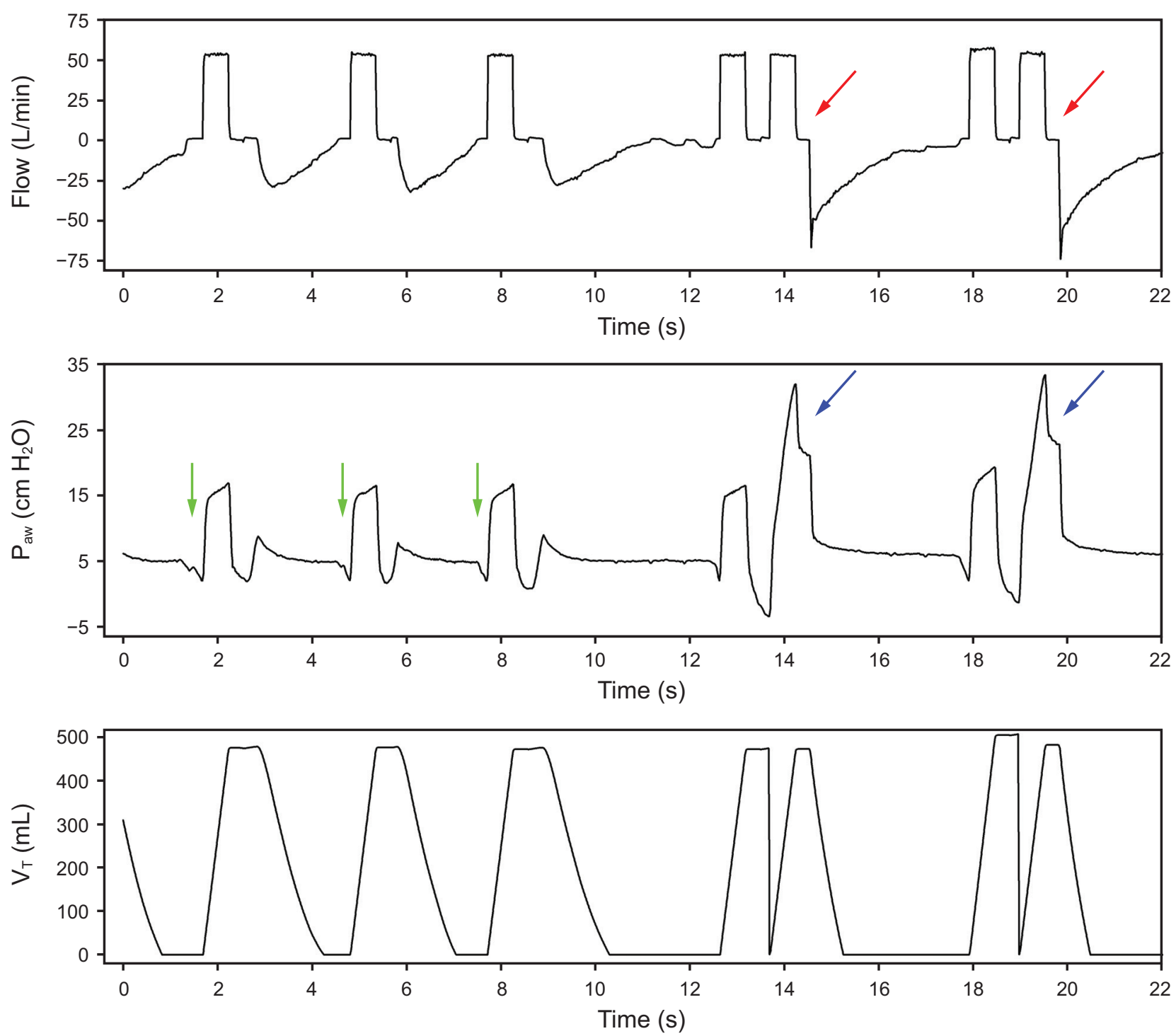

Fig. 2. Flow starvation with double-triggering seen on tracings of air flow, airway pressure $\left(P_{a w}\right)$, and tidal volume $\left(V_{T}\right)$ in a mechanically ventilated patient on volume-control continuous mandatory ventilation. Flow starvation (ie, inspiratory flow mismatching) occurs when the ventilator fails to meet the patient's flow demand. Inspiratory effort continues during mechanical insufflation (green arrow in the $P_{\text {aw }}$ waveform) in each breath; sometimes it is strong enough to trigger a second mechanical insufflation (red arrow) without expiration (ie, double-triggering ) and consequent breath-staking (blue arrows). Notice that the $\mathrm{V}_{\mathrm{T}}$ in breath-stacking is almost double with the associated elevated $\mathrm{P}_{\text {aw }}$.

dyspnea was associated with anxiety, continuous mandatory ventilation, and tachycardia. Increasing $\mathrm{V}_{\mathrm{T}}$ or inspiratory flow improved dyspnea in $35 \%$ of subjects, and extubation failure was more common in those whose dyspnea persisted after adjustment of ventilator settings. Therefore, after deciding on an appropriate, safe effort for a given patient, dyspnea must be assessed. Trained physicians, respiratory therapists, and nurses, regardless of their competence and years working in the ICU, normally underestimate patients' selfreported assessments. ${ }^{35}$ Most patients cannot communicate, so bedside algorithms might be useful. ${ }^{36}$ Finally, the potential consequences of low assistance include excessive respiratory muscle load and limbic, paralimbic, and cerebellar activation in the brain that can promote air hunger. ${ }^{37-41}$

\section{Short-Cycling: Double-Triggering and Breath-Stacking}

Short-cycling is defined as a breath cycle where the inspiratory time is less than one half of the mean inspiratory time. Double-triggering (breath-stacking) refers to 2 complete inspirations separated by a very short expiratory time; 

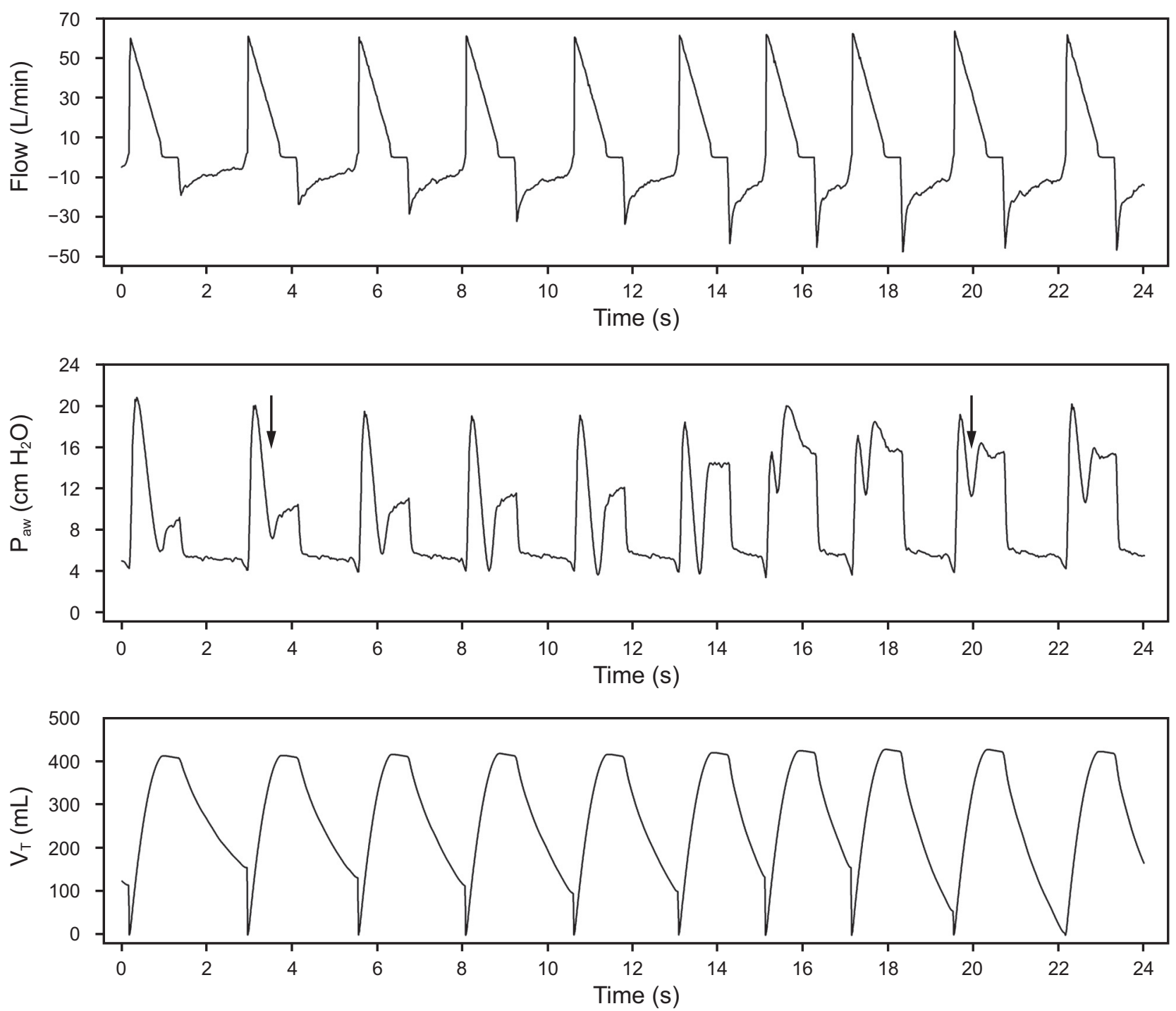

Fig. 3. Flow starvation seen on tracings of air flow, airway pressure $\left(P_{a w}\right)$, and tidal volume $\left(V_{T}\right)$ in a mechanically ventilated patient on volumecontrol continuous mandatory ventilation with decelerating flow. Flow starvation (ie, inspiratory flow mismatching) occurs when the ventilator fails to meet the patient's flow demand. Inspiratory effort continues during mechanical insufflation in each breath. Notice a negative deflection in the $\mathrm{P}_{\mathrm{aw}}$ waveform (arrow) with a different magnitude in every breath.

however, the classic definition of double-triggering takes into account only the expiratory time (ie, lower than one half of the mean inspiratory time) without incorporating a $\mathrm{V}_{\mathrm{T}}$ threshold. ${ }^{42}$ For this reason, some authors insist that doubletriggering cannot be used as a synonym for breath-stacking, and that the term breath-stacking should be used only to refer to the clinical consequence of double-triggering when incomplete exhalation between breaths results in a higher-than-intended $\mathrm{V}_{\mathrm{T}}{ }^{43}$

The underlying mechanism in both short-cycling and double-triggering is a mismatch between the patient's and ventilator's inspiratory times that causes the patient's inspiratory effort to persist beyond the end of the ventilator's inspiratory cycle; thus, the inspiratory muscles are still active at the beginning of machine expiration, impeding the elastic recoil of the respiratory system from increasing alveolar pressure (Fig. 4). In this circumstance, peak expiratory flow is aborted, and, if the patient's effort is sufficiently long and strong to reach the inspiratory trigger threshold, a second ventilator breath is delivered (Fig. 5). Consequently, to a similar pathophysiological mechanism, which of both asynchronies develops depends mostly on the ventilator mode and setting. For instance, when a sustained inspiratory effort persists or is strong enough to overcome the inspiratory trigger threshold in PSV, short-cycling or double-triggering could develop, because in PSV a decrease in inspiratory flow from its peak to a preset threshold triggers the ventilator's expiratory cycle. By 

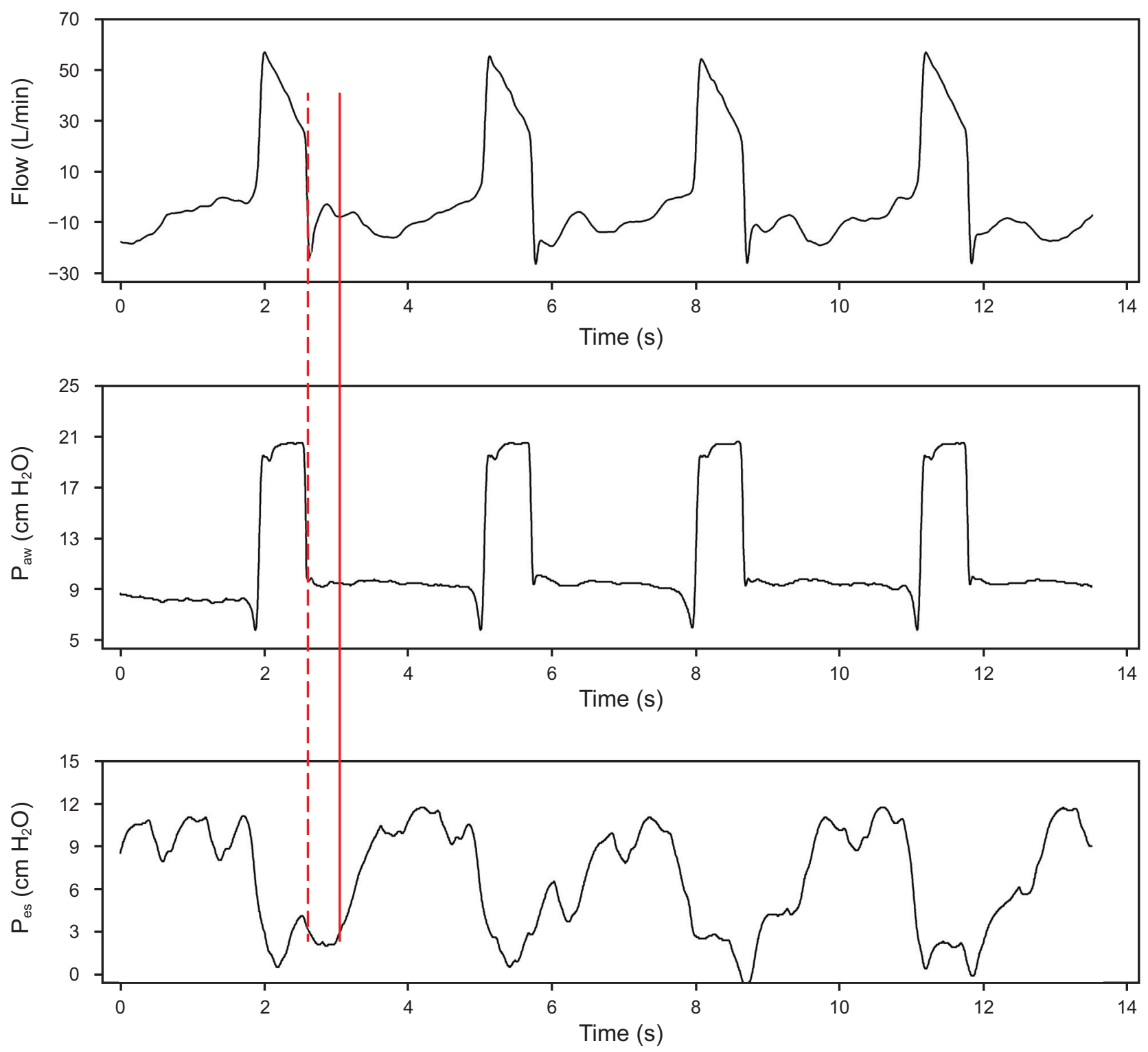

Fig. 4. Short or premature cycling seen on tracings of air flow, airway pressure $\left(P_{\text {aw }}\right)$, and esophageal pressure $\left(P_{\text {es }}\right)$ in a mechanically ventilated patient on pressure-control continuous mandatory ventilation. Every breath delivered is patient-triggered (ie, assist ventilation) with a decrease in flow, $\mathrm{P}_{\mathrm{aw}}$, and $\mathrm{P}_{\mathrm{es}}$. Short or premature cycling develops when the neural inspiratory time is greater than the mechanical inspiration time. In this example, the inspiratory effort (solid line) continues after the mechanical insufflation ended (dashed line), with the negative deflection of the $P_{\text {es }}$ persisting after the mechanical inflation terminates. This pattern develops in the 4 illustrative breaths. Image courtesy of Tai Pham and Laurent Brochard, Toronto, Canada.

contrast, in VC-CMV or PC-CMV, once the trigger threshold is reached, a complete second breath will be delivered and double-triggering with breath-stacking will occur, unless a preset pressure or volume alarm avert the second mechanical breath. ${ }^{44,45}$

Although uncommon, double-triggering is the second most frequent asynchrony. ${ }^{4,42,44}$ Longer inspiratory time and higher inspiratory peak flow are associated with less double-triggering, probably suggesting better matching among neural inspiratory time, ventilator inspiratory time, and inspiratory demand. Higher PEEP is also associated with less double-triggering, probably because higher lung volumes decrease inspiratory efforts. On the other hand, low peak pressure is associated with more double-triggering, secondary to flow asynchrony. ${ }^{44,46}$

Activation of inspiratory muscles during mechanical deflation results in an eccentric contraction of the diaphragm that can injure respiratory muscles. ${ }^{6,47-49}$ When breath-stacking occurs, the higher $\mathrm{V}_{\mathrm{T}}$ delivered can generate high transpulmonary and transvascular pressure gradients, as well as elevated local stress and uneven distribution of pressure in dependent zones of the lung (Fig. 3), ${ }^{14}$ which could cause ventilator-induced lung injury ${ }^{14,44,46,50}$ Double-triggering can occur in clusters in 

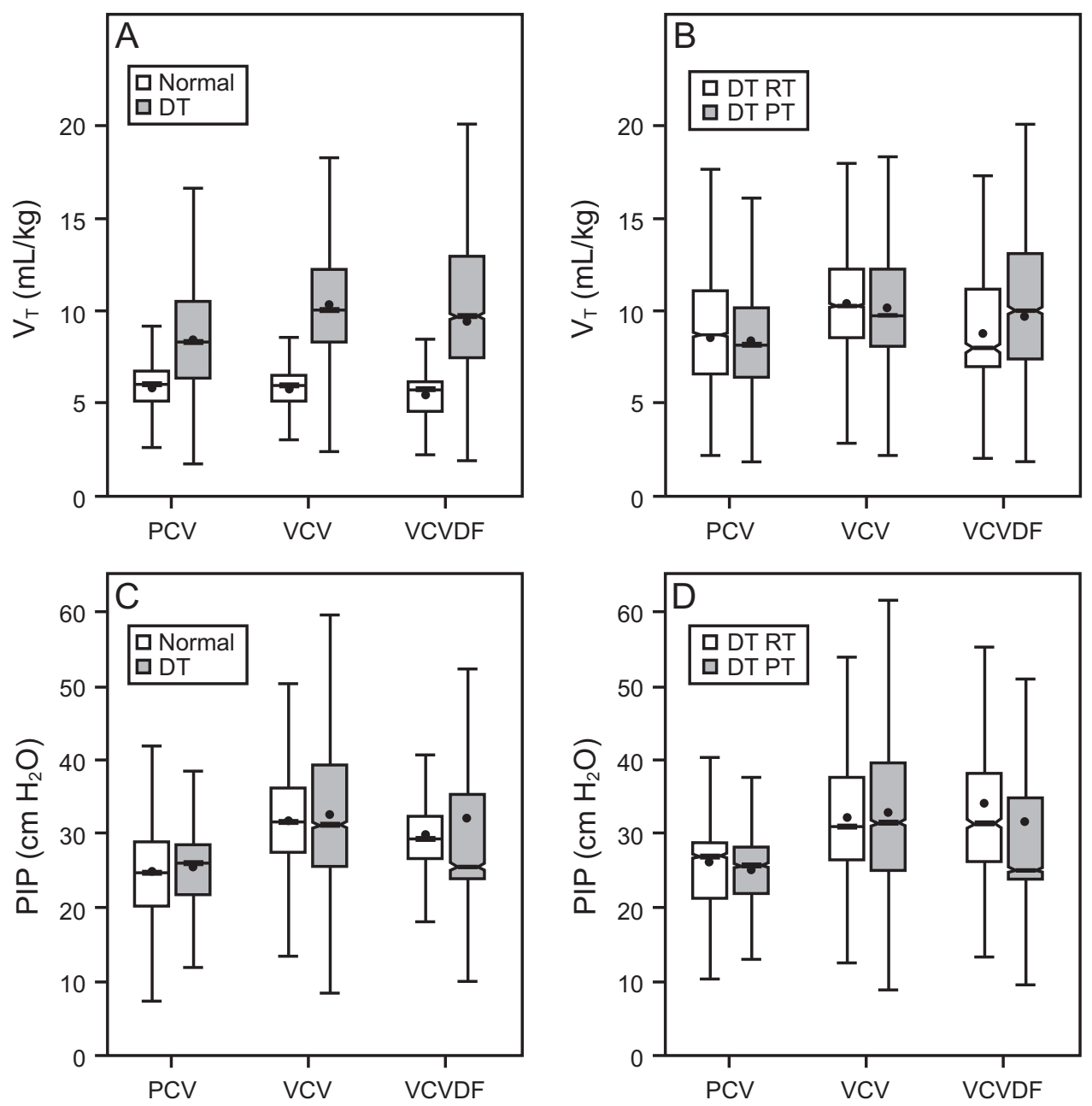

Fig. 5. Relationship between tidal volume $\left(\mathrm{V}_{\mathrm{T}}\right)$ and peak inspiratory pressure (PIP) in a normal breath and in a double-tirggered breath, with or without reverse-triggering. Descriptive notched boxplots for $V_{T}$ (top) and PIP (bottom) in each ventilatory mode. (A, C) Breaths without doubletriggering (DT) versus breaths with DT breaths. (B, D) Breaths with reverse-trigger-induced DT breaths (DT RT) versus patient-triggered DT breaths (DT PT). Dots represent means, and box plots indicate medians and 25th-75th percentiles. PCV = pressure-control continuous mandatory ventilation; VCV = volume-control continuous mandatory ventilation with constant flow; VCVDF = volume-control continuous mandatory ventilation with decelerated flow. Notice the higher $\mathrm{V}_{\mathrm{T}}$, in both patient-triggered and reverse-triggered ventilation, delivered in doubletriggered breaths without meaningful changes in PIP. From Reference 44, with permission.

patients with $\mathrm{ARDS}^{43}$ or in general ICU patients, ${ }^{44,46}$ but the prevalence of short-cycling or double-triggering or reverse-triggering is unknown.

\section{Overassistance: Patients With Low Respiratory Drive}

\section{Ineffective Efforts}

Ineffective efforts (IEs) are the most frequent type of asynchrony, affecting nearly $50 \%$ of mechanically ventilated patients. ${ }^{11,42,51,52}$ Defined as an inspiratory muscle effort that is not followed by a ventilator breath, IE occurs when the patient's attempt to initiate a breath does not reach the ventilator's trigger threshold (ie, when the ventilator fails to detect the patient's inspiratory effort). Patients experiencing IE often seem calm, without signs of dyspnea. For diagnostic purposes, a decrease in airway pressure associated with an increase in flow during expiration on tracings is highly suggestive of IE; a negative deflection in esophageal pressure or an increase in the electrical activity of the diaphragm not followed by a mechanical breath is confirmatory.

IE can result from different clinical conditions and reflect different situations. The main causes are delayed cycling, overassistance, and hyperinflation, all of which lead to intrinsic PEEP. ${ }^{52-55}$ Decreasing respiratory drive by other mechanisms such as sedation increases the occurrence of IE, and deeper sedation with propofol is associated with higher frequency of IE during PSV (see Management). ${ }^{56,57}$ Entrainment and reverse-triggering 
could also induce IE if they occur in the late inspiratory phase or early expiratory phase (see Reverse-Triggering: Entrainment Phenomenon).

The main clinical consequence of IE is muscle damage. In the context of overassistance, IE can lead to myofibrillar atrophy and contractile dysfunctions in a short time (overassistance myotrauma) ${ }^{15,47}$ Excessive contractile loading while the muscle is lengthening (eccentric contractions) are particularly injurious; this eccentric myotrauma occurs when the muscle contracts actively during the ventilator expiratory phase. ${ }^{47,54,58}$ The higher levels of support and increased $V_{T}$ provided by PSV decrease dyspnea, resulting in decreased drive and a progressive increase in IE. $^{53}$ Plotting the level of assistance in PSV and dyspnea yields a U-shaped curve (Fig. 6); if assistance is too high or too low, discomfort increases. ${ }^{31,51}$ Thus, clinicians should individualize support, aiming for the midpoint that avoids both excessive and insufficient assistance.

\section{Delayed or Prolonged Cycling}

Prolonged cycling occurs when mechanical insufflation continues after the end of neural inspiration, sometimes even when the patient is actively exhaling (Fig. 7). When this occurs, the patient may actually fight the ventilator, recruiting expiratory muscles in an attempt to force expiration. Prolonged cycling is associated with the failure of the subsequent inspiratory effort to trigger the ventilator. ${ }^{54}$

In PSV, the ventilator expiration cycle begins when flow decreases to a set percentage of peak inspiratory flow. Insufflation tends to be longer with higher levels of support and with increased air flow resistance. Additionally, higher levels of support result in a higher peak flow that may shorten the neural inspiration time, exacerbating the mismatch between the patient and the ventilator. ${ }^{59}$ In this scenario, the inspiratory flow delivered decreases very slowly, and the flow-cycling mechanism can cause the ventilator's inspiratory time to be longer than the neural inspiratory time. This overassistance results in hyperventilation, hypocapnia, and respiratory alkalosis, reducing respiratory drive and increasing asynchronies in a vicious circle. ${ }^{60}$ Furthermore, the continuous recruitment of expiratory muscles is associated with failed weaning trials. ${ }^{61,62}$ Finally, other, nonrespiratory mechanisms, such as airway leaks, can also cause prolonged cycling, so it is important to check endotracheal tubes and cuffs, tracheostomy tubes, and the entire artificial circuit.

\section{Reverse-Triggering: Entrainment Phenomenon}

The respiratory center is a biological oscillator, so it is susceptible to entrainment from the periodic imposition of input from the ventilator; in other words, periodic lung inflation can establish a fixed repetitive temporal relationship between the neural and mechanical respiratory cycles. ${ }^{63}$ This phenomenon has been observed in rabbits, ${ }^{64,65}$ cats, ${ }^{63,66}$ dogs, and humans. ${ }^{67,68}$ Entrain-ment develops more often when the ventilator's $V_{T}$, breathing frequency, and inspiratory flow are very similar to the subjects' neural breathing pattern. The pathophysiology of entrainment probably involves the slowly adapting and rapidly adapting stretch receptors in the lungs as well as vagal C-fibers. Nevertheless, entrainment has also been observed in vagotomized lung transplant recipients ${ }^{68}$ and in brain-dead patients in the absence of respiratory drive from the brainstem, ${ }^{69}$ so respiratory muscle activation after ventilator insufflation is likely mediated by various afferents.

Recently, the term reverse-triggering was coined to describe an asynchrony that results from respiratory entrainment. ${ }^{70}$ In reverse-triggering, mechanical insufflation elicits a neural response, resulting in neural and muscular activity that ends in a ventilator-induced diaphragmatic contraction. It is important to emphasize that entrainment is not an asynchrony, but rather the mechanism underlying reverse-triggering. Moreover, once entrainment develops, reverse-triggering could induce other asynchronies, such as IE and double-triggering, so from a clinical viewpoint it could be useful to distinguish IE, double-triggering, and breath-stacking induced by invasive ventilation from those developing through other pathophysiological mechanisms (Fig. 8).

Reverse-triggering can be classified by the ratio of mechanical breaths to diaphragmatic contractions. The most common pattern observed in animal models and in humans is $1: 1$, but ratios of $2: 1$ and $3: 1$ have been reported. ${ }^{64,66,70}$ The only reliable way to recognize reverse-triggering is by detecting the muscle contraction after mechanical insufflation in esophageal pressure measurements, although careful analysis of ventilator waveforms could also indicate reverse-triggering. ${ }^{44,70-72}$ Automated algorithms promise to detect reverse-triggering from ventilator waveforms reliably and quickly without the need for esophageal pressure monitoring. ${ }^{73}$

Reverse-triggering can lead to lung and muscle injury. Once IE or double-triggering induced by invasive ventilation develops, the pathophysiological mechanism of injury is the same as when these asynchronies develop from other causes. Su et $\mathrm{al}^{74}$ reported that $30 \%$ of subjects with ARDS exhibit reverse-triggering that developed in the late inspiratory phase (41\%) and early expiratory phase (59\%), and that reverse-triggering was associated with breath-stacking with a larger proportion of $\mathrm{V}_{\mathrm{T}}$ and maximum transpulmonary pressure fluctuations compared to passive breaths, suggesting that the mechanism of injury is not only volutrauma but also barotrauma. Interestingly, in one subject with ARDS, Yoshida et $\mathrm{al}^{75}$ observed that reverse-triggering without breath-stacking elicited an injurious inflation pattern with asymmetric stretch of the dependent lung at constant $\mathrm{V}_{\mathrm{T}}$. 

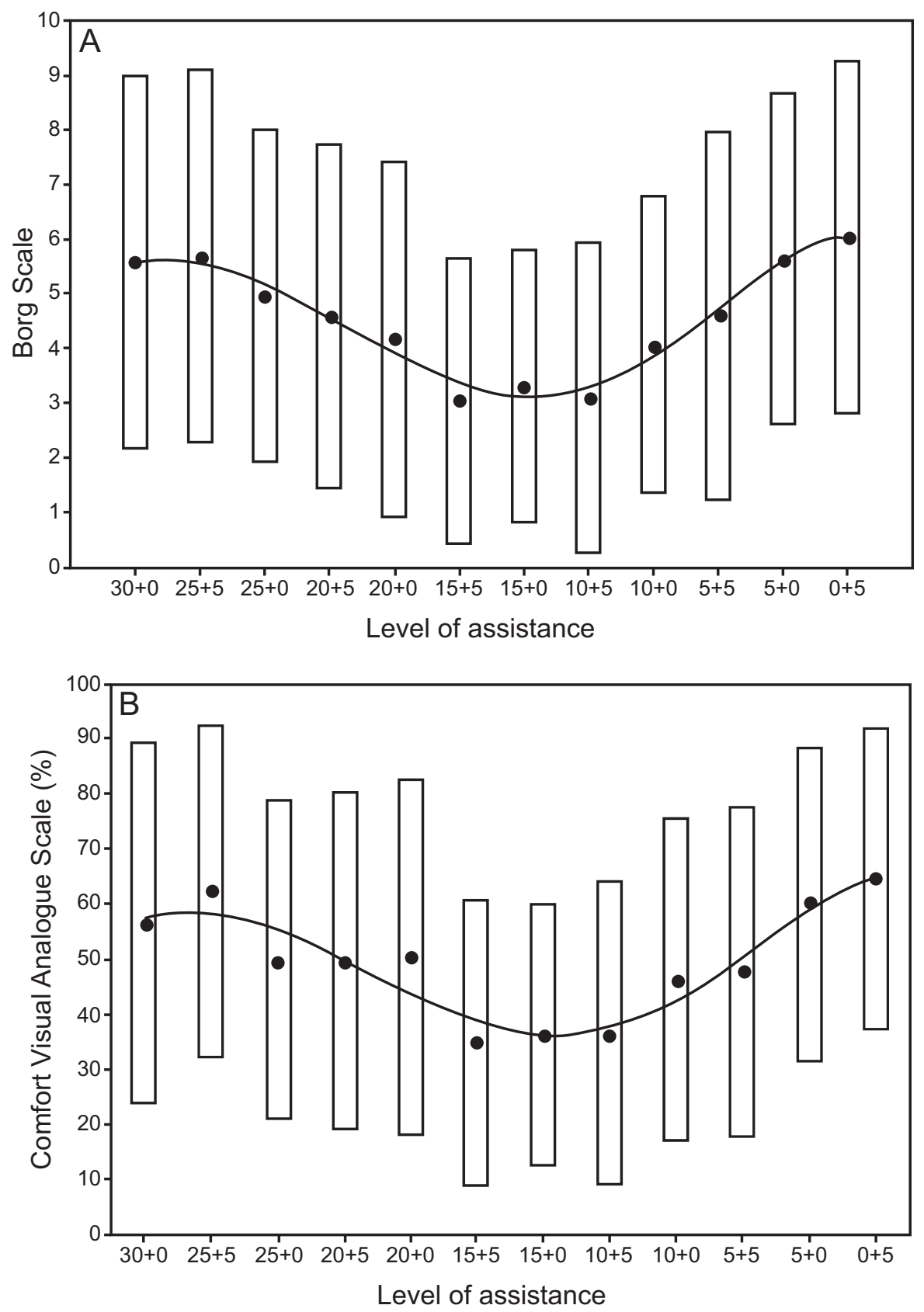

Fig. 6. Relationship between comfort and level of assistance. Patient comfort was assessed with 2 different methods: (A) Borg scale; (B) visual analog scale. Notice that the extreme levels of assistance during pressure support ventilation generated the least comfort. From Reference 51 , with permission.

At present, our understanding of the prevalence and clinical meaning of reverse-triggering in mechanical ventilation patients is very limited because this phenomenon was discovered only recently, so few clinicians are familiar with it and trained to identify it. ${ }^{70,76}$ Observational studies have often reported reverse-triggering in heavily sedated subjects with ARDS, but less information is available about the prevalence of reverse-triggering in other clinical scenarios. ${ }^{70,74,75}$ Although de Haro et $\mathrm{al}^{44}$ reported that double-triggering induced by invasive ventilation occurred in $34.6 \%$ of a cohort of 67 general ICU subjects, further studies are needed to investigate this issue in different groups of patients to better understand reverse-triggering and its clinical implications.

\section{Assessment of Asynchronies}

Asynchronies can be detected with different techniques, including the analysis of flow-time, pressure- 


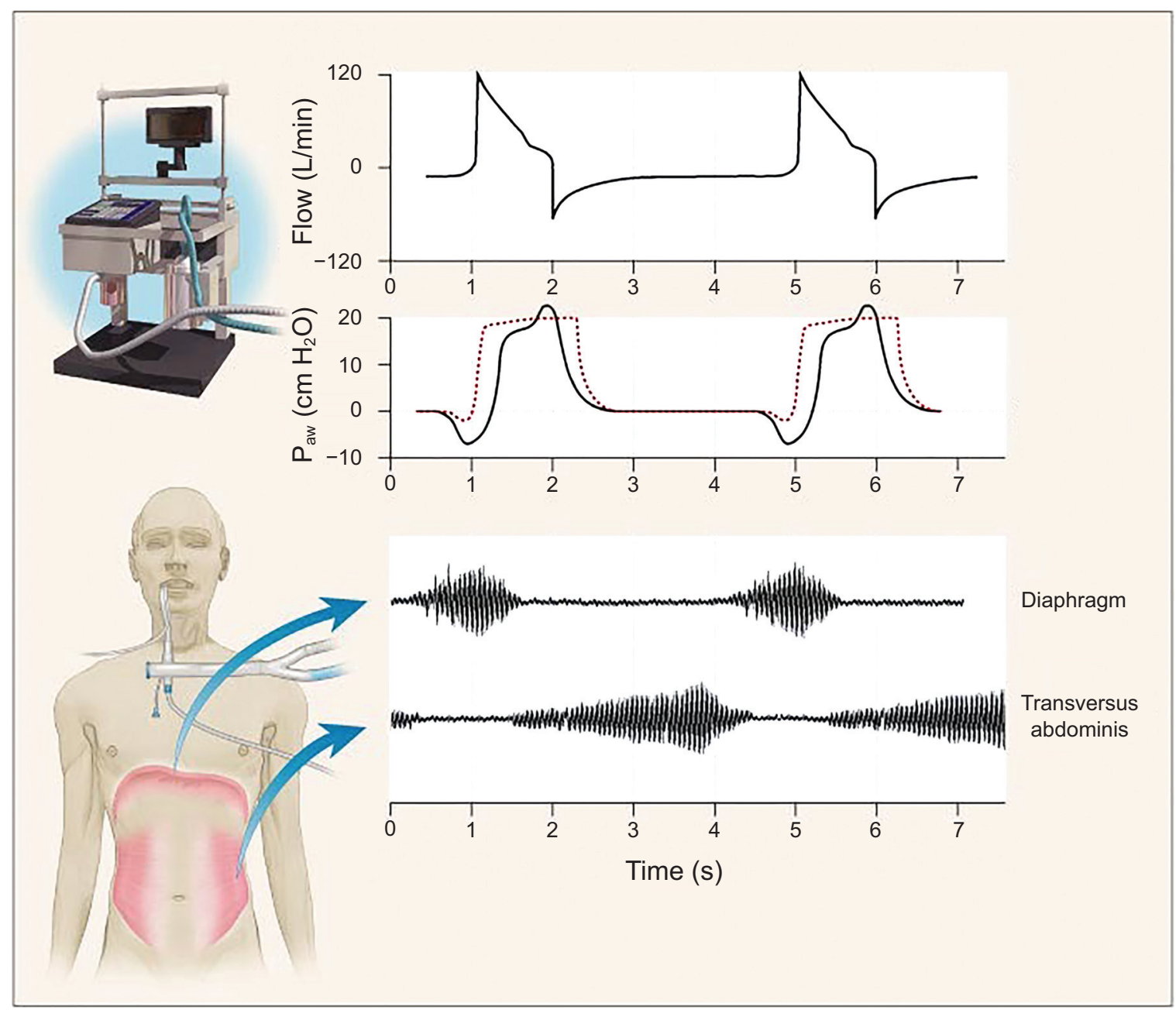

Fig. 7. Flow, airway pressure $\left(\mathrm{P}_{\mathrm{aw}}\right)$, and inspiratory and expiratory muscle activity in a patient with COPD who received pressure support ventilation with delayed or prolonged cycling. The electromyograms in the lower portion of the figure show inspiratory muscle activity in the patient's diaphragm and expiratory muscle activity in the transversus abdominis. The patient's increased inspiratory effort caused $\mathrm{P}_{\text {aw }}$ to fall below the set trigger threshold, and inadequate delivery of flow by the ventilator resulted in a scooped contour on the $P_{\text {aw }}$ curve during inspiration. Although the ventilator was still pumping gas into the patient, his/her expiratory muscles were recruited, causing a bump in the $\mathrm{P}_{\mathrm{aw}}$ curve. Notice that neural inspiratory time is not coupled with machine inspiratory time; after the neural inspiration finished, the ventilator still provided air flow while the patient's expiration begins. The dotted line shows $\mathrm{P}_{\mathrm{aw}}$ in another patient who generated just enough effort to trigger the ventilator and in whom there was adequate delivery of gas by the ventilator. From Reference 3, with permission.

time, and integrated-volume waveforms from ventilator screens; tracings from balloon-tipped esophageal catheters; electrical activity of the diaphragm, which is available on some ventilators; and more recently, automated algorithms (10).

The sensitivity and positive predictive value of analyzing breath-to-breath waveforms are very low $(22 \%$ and $32 \%$, respectively); even trained physicians recognize less than one third of asynchronies. Clinicians' ability to identify asynchronies by visual inspection is partially influenced by their expertise and the type of asynchrony. ${ }^{77}$ Adding analyses of esophageal pressure tracings could improve the recognition of IE, short-cycling, reverse-triggering, and high efforts during flow asynchrony. ${ }^{78,79}$ Unfortunately, although it is minimally invasive, esophageal pressure monitoring is not routine in mechanically ventilated patients, and proper balloon placement and data interpretation require experience. The electrical activity of the diaphragm provides reliable information about patients' inspiratory and expiratory time, but it is only available in Servo (Maquet, Sweden) ventilators in the neurally adjusted ventilation assist (NAVA) mode, and the position of the catheter must be checked periodically for displacement and adjusted to ensure correct positioning. ${ }^{80}$ More importantly, it is not only the recognition of asynchronies that matters, but also their frequency and 

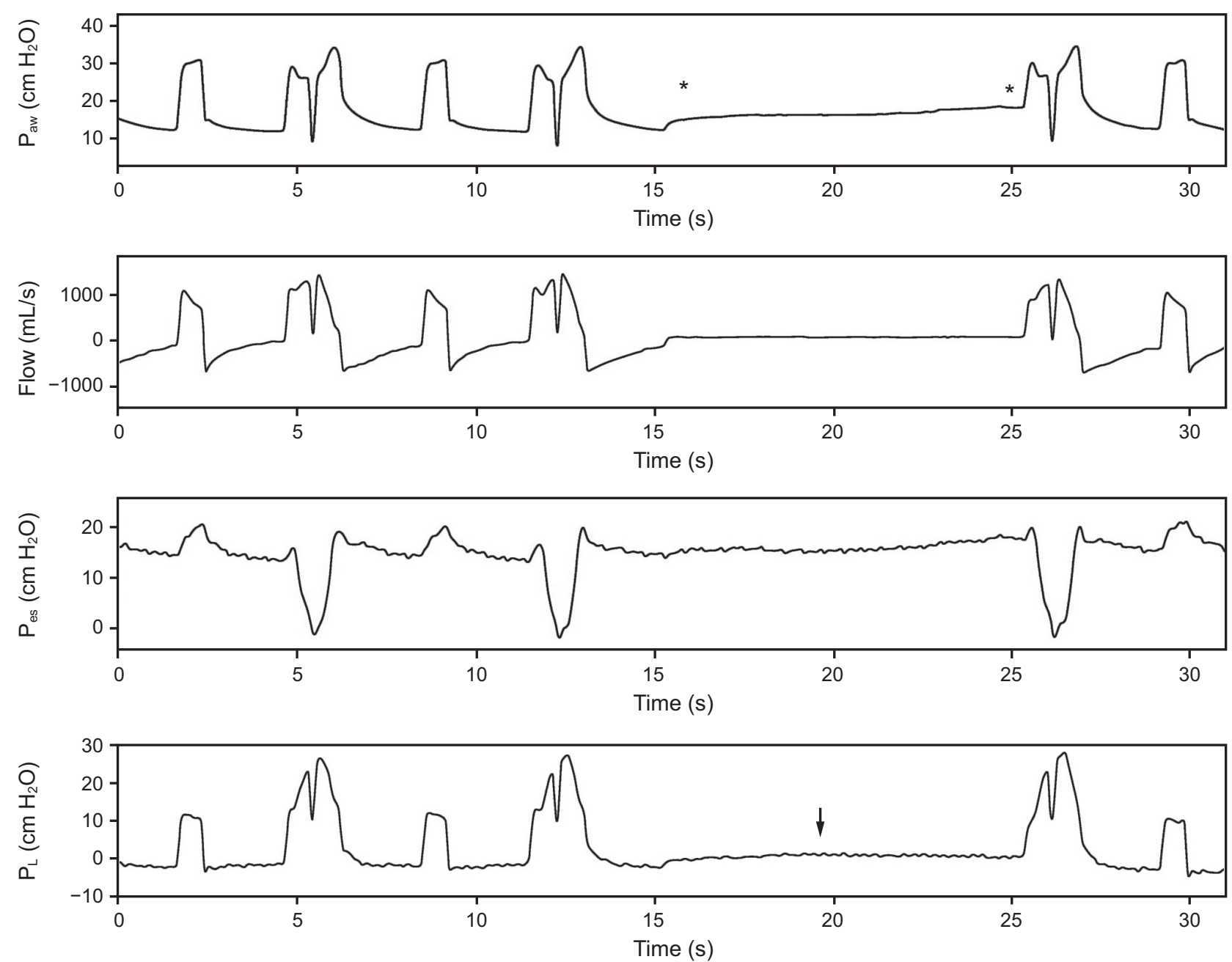

Fig. 8. Reverse-triggering and elimination of reverse-triggered breaths during an end-expiratory hold: airway pressure $\left(P_{\text {aw }}\right)$, flow, esophageal pressure $\left(\mathrm{P}_{\mathrm{es}}\right)$, and transpulmonary pressure during 6 breaths and an expiratory hold. The first 4 breaths show signs of respiratory entrainment; there seems to be a 2:1 pattern of mandatory breaths to reverse-triggered breaths that start as a passive insufflation but are rapidly followed by patient effort, as can be concluded from the drop in $\mathrm{P}_{\mathrm{es}}$ (ie, the mandatory insufflations elicit a neural response that leads to patient effort). Larger drops in $\mathrm{P}_{\mathrm{es}}$ than in $\mathrm{P}_{\mathrm{aw}}$ trigger the ventilator before exhalation of the previous breath, leading to breath-stacking with high tidal volumes. These breaths with patient effort are likely reverse-triggered. An expiratory hold was administered at the first asterisk and continued until the next asterisk, which abolished respiratory muscle activity for $>12 \mathrm{~s}$. The arrow on the transpulmonary pressure $\left(P_{\llcorner}\right)$curve marks the moment that inspiratory effort was expected if patient effort was generated spontaneously. After the expiratory hold, another mandatory insufflation was administered by the ventilator; patient effort immediately follows. This is suggestive of reverse-triggering because the patient effort seems to depend on the external stimulus provided by mandatory ventilator insufflation. From Reference 71, with permission.

distribution over time; asynchronies can occur anytime during mechanical ventilation and often occur in clusters alternated with periods without dyssynchronies (Fig. 9). ${ }^{4,43,44,81,82}$

Various automated algorithms have been developed and validated to detect asynchronies through the continuous analysis of flow-time and pressure-time tracings, although their performance varies. ${ }^{4,44,73,83,84}$ Another algorithm is based on the automated spectral analysis of flow signal. ${ }^{85}$ Given the clustering of patient-ventilator asynchronies, automated detection, prediction, and intelligent alarms promise to be more accurate than time-consuming visual inspection of waveforms, which can only detect dyssynchronous events occurring during the actual observation period.

\section{Asynchronies and Sleep in Critically IIl Patients}

Nearly all patients in medical, cardiac, and surgical ICUs have fragmented sleep, with long sleep-onset latency, rapideye-movement latency, and poor sleep efficiencies. ${ }^{86-90}$ Although the amount of sleep over a 24-h period may be relatively normal (7-9 h), short bouts during the day account for approximately $50 \%$ of this total. ${ }^{91,92}$ Deranged sleep 

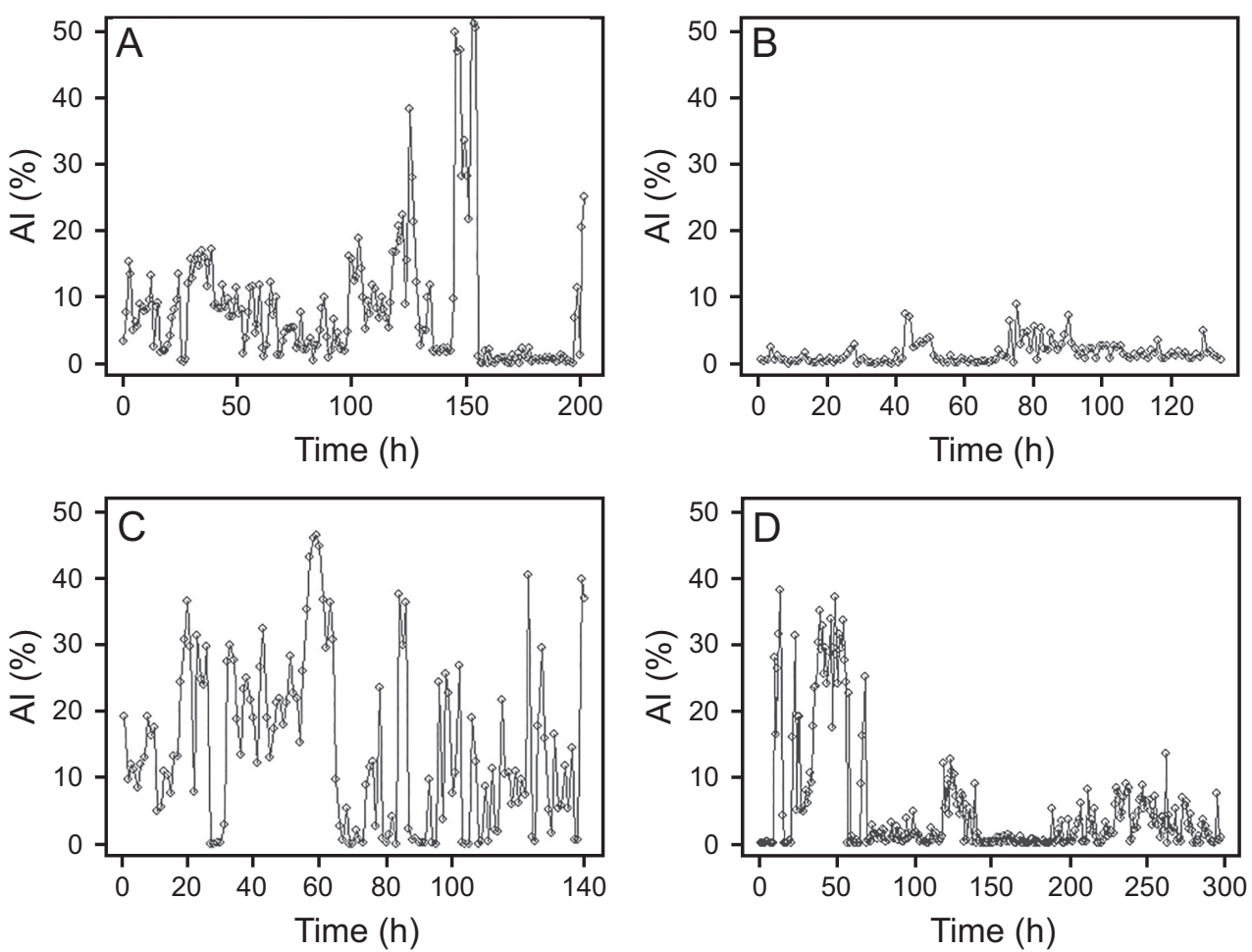

Fig. 9. Distribution of asynchronies during mechanical ventilation. The asynchrony index, noted as percentage (\%) per hour, was recorded continuously over several days in 4 representative patients. Recordings show that periods of very low asynchrony alternated with periods of high levels of asynchrony. From Reference 4, with permission.

architecture is associated with ICU delirium..$^{93}$ In mechanically ventilated patients, noise, stress related to increased difficulty in communicating, dyssynchronous breathing, ventilator modes, drugs, and discomfort can further degrade the quality of sleep. ${ }^{91,94,95}$ Meza et $\mathrm{al}^{96}$ and Parthasarathy et $\mathrm{al}^{97}$ reported that sleep fragmentation could be induced by increasing support on PSV. This was explained by a decreased drive during sleep but with the same support that resulted in overassist, thus causing hypocapnia. Thille et $\mathrm{al}^{98}$ recently reported that time to weaning was $3 \mathrm{~d}$ longer in patients with atypical sleep.

Hypothesizing that asynchronies cause sleep fragmentation, 3 studies compared newer, proportional modes of mechanical ventilation designed to improve patient-ventilator synchrony $\left(\mathrm{PAV}+{ }^{99,100}\right.$ and NAVA $^{101}$ ) with PSV. All 3 studies reported that the newer modes reduced asynchronies during sleep, but the effects on sleep quality were small, improving it in 2 studies ${ }^{100,101}$ and worsening it in the other ${ }^{99}$ However, as Younes ${ }^{94}$ pointed out, fighting the ventilator during wakefulness may prevent patients from falling asleep until they are no longer able to fight, are sedated, or are exhausted. Hence, the deleterious effect of an unsuitable ventilation mode may be present only when the patient is awake, and the impact would be reduced sleep time and not poor-quality sleep. Our understanding of the relationships between patient-ventilator interactions and sleep is currently growing and constantly evolving.

\section{Management}

As is common in clinical medicine, better understanding of the mechanisms underlying asynchronies can improve treatment. Respiratory drive in ICU patients can be affected by many factors, including pain, temperature, inflammatory chemokines, deranged gas exchange, metabolic demands, neurological insults, and even behavioral factors and sleep state, thus modifying mechanical feedback (ie, the effects of volume and flow delivered by the ventilator upon the respiratory muscles), reflex feedback (ie, the influence of various receptors located in the lungs, chest wall, and respiratory tract upon delivered volume and flow), chemical feedback (ie, the ventilatory response to chemical stimuli driven by $\mathrm{CO}_{2}, \mathrm{pH}$, and $\mathrm{O}_{2}$ ), and behavioral feedback (ie, the effects of cortical output on control of breathing). ${ }^{1,2,13,40,102-104}$ Thus, before attempting to correct an asynchrony, clinicians should address modifiable medical issues with careful examination of ventilator performance 


\section{Monitoring Asynchrony During InVasive Mechanical Ventilation}

and the circuit to allow optimal neuromechanical coupling whenever possible.

The 2 most common approaches to dealing with asynchronies are sedation or analgesia and adjusting ventilator settings. Clinicians list promoting patient-ventilator synchrony among the main reasons for administering sedatives, but increasing sedation is associated with worse short- and long-term outcomes. ${ }^{105-108}$ Thus, a more conservative strategy minimizing the use of sedatives during mechanical ventilation is currently recommended. ${ }^{109-112}$ Sedatives influence respiratory center output by affecting either the respiratory drive or timing. When deeper levels of sedation diminish the respiratory drive, IE develops. ${ }^{56,57}$ One study reported that the IE index increased by $2.7 \%$ for every 1 -unit decrease in the Richmond Agitation-Sedation Scale. ${ }^{57}$ Another report noted that the extent to which propofol reduced neural drive varied with the rate of infusion and that deeper sedation increased IE in PSV but not in NAVA. ${ }^{56}$ The results of a recent study considering the entire period of mechanical ventilation in 79 subjects, in whom $>14$ million breaths were analyzed, ${ }^{113}$ shed new light on the usefulness of sedatives and opioids in treating asynchronies (Fig. 10). Sedatives, whether administered alone or together with opioids, did not decrease asynchronies beyond what was achieved with opioids alone. Moreover, opioids were inversely associated with IEs, double-triggering, and asynchrony index, but when sedatives were added to the regimen, increased doses of sedatives were associated with higher IE and asynchrony index values. Additionally, unlike opioids alone, sedatives, used alone or in combination with opioids, were inversely associated with the level of consciousness. Thus, increasing sedation to improve patient-ventilator interaction might have the opposite result. The different effects of sedatives and opioids on asynchronies, level of consciousness, and dyspnea are presented in Table 1.

Dealing with the underlying cause of asynchronies by adjusting ventilator settings should be the preferred approach. A single-center study in patients receiving VC-CMV, most with breath-stacking, reported that ventilator adjustments were more effective than increasing sedation. ${ }^{50}$ Table 2 summarizes the different ventilatory amendments that could be used to correct each type of asynchrony. It is important to consider the physiological concepts involved, because ventilator output affects patient output and vice versa, so any change in ventilator settings (eg, $\mathrm{V}_{\mathrm{T}}$, flow, inspiratory time, rise time, etc.) will alter the activity of the mechanoreceptors and neuromechanical feedback.

Managing flow asynchrony could be particularly challenging. It might be tempting to correct flow starvation by increasing the flow delivered; however, in parallel experiments, Laghi et $\mathrm{al}^{114}$ and Fernandez et $\mathrm{al}^{59}$ reported that increasing the flow at a constant $\mathrm{V}_{\mathrm{T}}$ decreases neural inspiratory time, thereby increasing the breathing frequency. Thus, managing high IE due to insufficient flow requires not only increasing the delivered flow to mitigate flow starvation, but also close observation of the resultant breathing pattern to avoid dynamic hyperinflation due to insufficient expiratory time ${ }^{45,52}$ Moreover, inspiratory-flow mismatch could be related to inadequate pressurization of the system unrelated to the patient's inspiratory flow demand.

If a patient can breathe spontaneously, proportional modes might offer some advantages in certain patients. Several studies reported fewer major asynchronies and a greater proportion of time in synchrony with the ventilator with PAV+ than with PSV, even in patients with COPD. ${ }^{99,115-117}$ Numerous studies found similar results for NAVA versus PSV. ${ }^{118-121}$ Additionally, an ongoing study to determine whether PAV+ could improve outcomes is currently enrolling subjects (ie, the PROMIZING study; ClinicalTrials.gov: NCT02447692).

Another promising approach is partial neuromuscular blockade. In a proof-of-concept study of subjects recovering from ARDS who were able to breathe spontaneously in PSV but developed high $\mathrm{V}_{\mathrm{T}}(>8 \mathrm{~mL} / \mathrm{kg}$ predicted body weight), continuously infusing low doses of rocuronium facilitated lung-protective ventilation by decreasing $V_{T}$ and transpulmonary pressure while reducing work of breathing and maintaining diaphragmatic activity. ${ }^{22}$ Even though asynchronies were not specifically measured, the physiological basis of this approach (ie, diminishing vigorous diaphragmatic contractions induced by high respiratory drive) suggests that when high drive cannot be controlled, regulating output (ie, high effort) could be effective; nevertheless, future studies should investigate this possibility.

\section{Outcomes}

Although many studies have explored possible associations between asynchronies and outcomes, none have been specifically designed to assess the impact of asynchronies on outcome. One study reported that the duration of mechanical ventilation was longer in subjects with an IE index $>10 \%$, although these conclusions were based on recordings of only 10 min during the first day of mechanical ventilation. ${ }^{122}$ Another study, based on 30-min recordings, also reported that the duration of mechanical ventilation was longer in subjects with asynchrony index $>10 \%$ who also had a higher incidence of tracheostomy, although mortality was unaffected..$^{42}$ By contrast, in a prospective noninterventional observational study using dedicated software to analyze asynchronies during mechanical ventilation in 50 subjects, Blanch et $\mathrm{al}^{4}$ reported that subjects with asynchrony index $>10 \%$ had rates of re-intubation and tracheostomy similar to subjects with fewer asynchronies, but higher ICU and hospital mortality and a trend toward longer 


\section{Monitoring Asynchrony During InVasive Mechanical Ventilation}
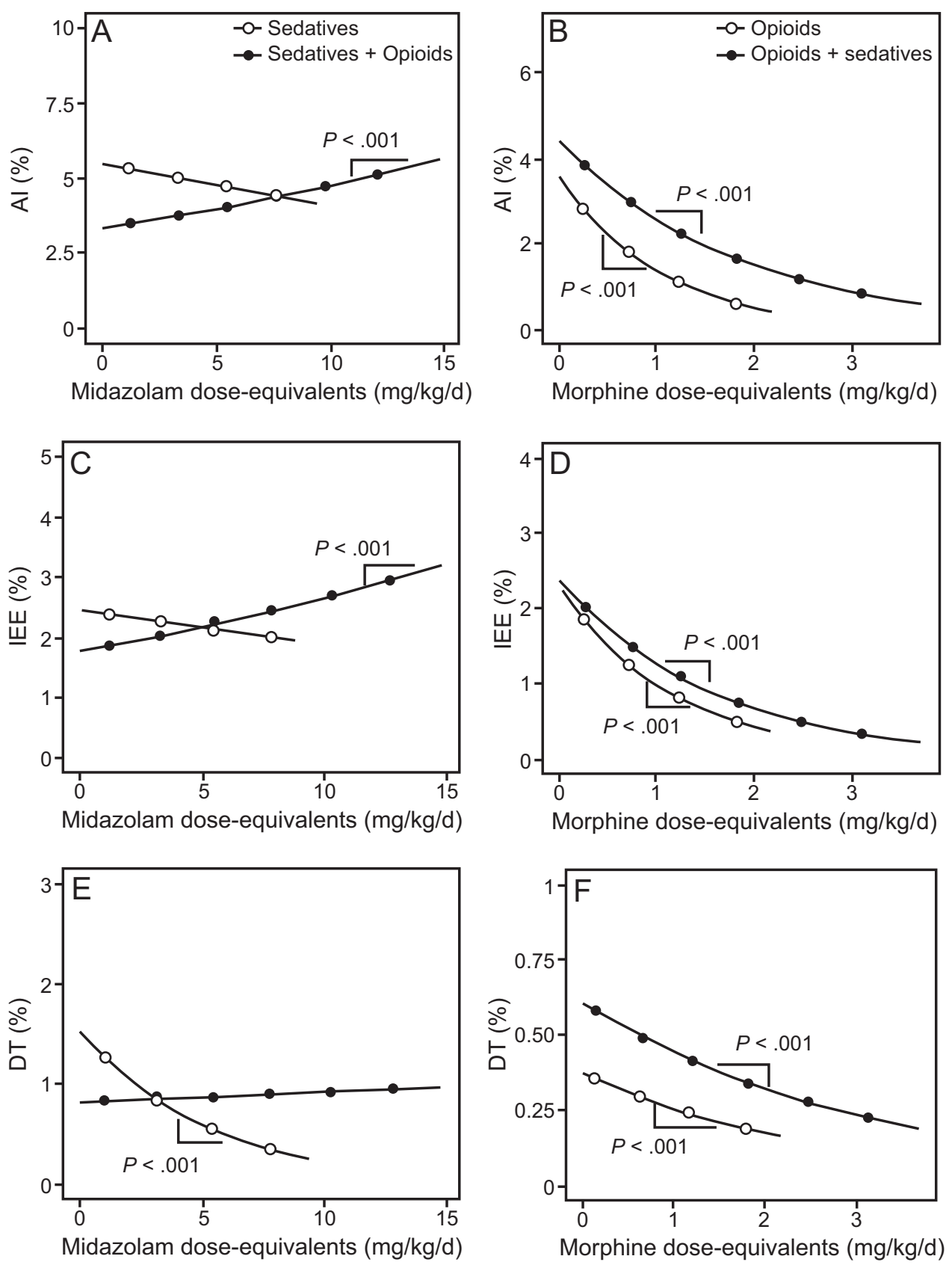

Fig. 10. Relationship between asynchrony and dose of sedatives (left) and opioids (right). On opioids-only days (white circles in B, D, F), the opioid dose was inversely associated with AI, IEE, and DC. On sedatives + opioids days (black circles in A, C, E), opioid dose was still inversely associated with AI, IEE, and DT. Sedative + opioid dose was directly associated with Al and IEE (black circles in A, C), but not with DT (black circles in E). On sedatives-only days (white cirlces in A, C, E), the sedative dose was only inversely related to DT. Al = asychrony index; $\mathrm{IEE}=$ ineffective expiratory effort; DT = double-triggering. From Reference 113, with permission.

duration of mechanical ventilation. Although this study used extensive real-world data, its design precludes definitive conclusions, and dyssynchronies could have been related to disease severity rather than a direct cause of mortality.

Asynchronies tend to occur in clusters between relatively uneventful periods, and clustering might be more important than overall rates for outcomes. Periods with almost no asychrony alternate with high rates of asynchronies around the clock, during the entire duration of mechanical ventilation. ${ }^{4}$ Other studies have reported clusters of particular asynchronies (eg, double-triggering and IE). Beitler et $\mathrm{al}^{43}$ noted that both the overall and peak hourly frequency of breath-stacking differed considerably among subjects. Defining clusters 


\section{Monitoring Asynchrony During InVasive Mechanical Ventilation}

Table 1. Relationships between ventilatory modes, drugs, asynchronies, and clinical effects

\begin{tabular}{|c|c|c|c|c|c|c|c|}
\hline \multirow{2}{*}{ Ventilatory Modes } & \multirow{2}{*}{ Drugs } & \multicolumn{4}{|c|}{ Asynchronies } & \multicolumn{2}{|l|}{ Clinical Effect } \\
\hline & & Ineffective Efforts & Double-Triggering & Flow Starvation & Reverse-Triggering & Level of Consciousness & Dyspnea \\
\hline $\begin{array}{l}\text { Volume-control } \\
\text { continuous } \\
\text { mandatory } \\
\text { ventilation }\end{array}$ & $\begin{array}{l}\text { Sedatives } \\
\text { Opioids }\end{array}$ & $\begin{array}{l}\downarrow^{82} \quad \uparrow^{57,113} \\
\downarrow^{113}\end{array}$ & $\begin{array}{l}\downarrow={ }^{50,82,113} \\
\downarrow^{113}\end{array}$ & $\begin{array}{l}\downarrow^{82} \\
\downarrow^{* \dagger}\end{array}$ & $\begin{array}{l}\uparrow^{70,75} \\
={ }^{*}\end{array}$ & $\begin{array}{l}\downarrow^{57,113} \\
={ }^{113}\end{array}$ & $\begin{array}{l}={ }^{*} \\
\downarrow^{* 32,33}\end{array}$ \\
\hline $\begin{array}{l}\text { Pressure support } \\
\text { ventilation }\end{array}$ & $\begin{array}{l}\text { Sedatives } \\
\text { Opioids }\end{array}$ & $\begin{array}{l}\uparrow^{56,57,113} \\
\downarrow^{113}\end{array}$ & $\begin{array}{l}\downarrow==^{50,113} \\
\downarrow^{113}\end{array}$ & $\begin{array}{l}\downarrow^{* \frac{*}{p}} \\
\downarrow^{*+}\end{array}$ & & $\begin{array}{l}\downarrow^{57,113} \\
={ }^{113}\end{array}$ & $\begin{array}{l}=^{*} \\
\downarrow^{* 32,33}\end{array}$ \\
\hline Sedatives + opioids & & $\begin{array}{l}>\text { Sed. } \uparrow \\
>\text { Op. } \downarrow\end{array}$ & $\begin{array}{l}>\text { Sed. }= \\
>\text { Op. } \downarrow\end{array}$ & $\begin{array}{l}>\text { Sed. } \downarrow^{* \hbar} \\
>\text { Op. } \downarrow^{* \dagger}\end{array}$ & $\uparrow^{70,75}$ & $\downarrow^{113}$ & $\downarrow^{*}$ \\
\hline $\begin{array}{l}\text { Sedatives include midazolan } \\
{ }^{*} \text { Considered effect, based o } \\
{ }^{\dagger} \text { Effect possibly mediated b } \\
{ }^{2} \text { Effect possibly mediated by } \\
=\text { No observed change }\end{array}$ & $\begin{array}{l}\text { propofol, and d } \\
\text { clinical judgmer } \\
\text { decreasing dysp } \\
\text { decreasing respi }\end{array}$ & $\begin{array}{l}\text { exmedetomidine; opioids inc } \\
\text { tt and physiological basis. } \\
\text { nea and air hunger. } \\
\text { ratory drive. }\end{array}$ & de morphine and fentanyl. & & & & \\
\hline
\end{tabular}

Table 2. Ventilator adjustments for managing asynchronies

\begin{tabular}{|c|c|}
\hline Asynchrony & Action \\
\hline Flow starvation & $\begin{array}{l}\text { Increase gas flow; decrease respiratory drive and assess adequacy of analgesia and sedation; } \\
\text { check for dyspnea. }\end{array}$ \\
\hline Short or prolonged cycling & $\begin{array}{l}\text { Increase or decrease inspiratory period; check cycling-off in pressure support; try } \\
\text { proportional modes, if suitable; check comfort and dyspnea. }\end{array}$ \\
\hline Double-triggering & $\begin{array}{l}\text { Increase ventilator inspiratory time; try pressure support, titrating flow termination criteria to } \\
\text { improve synchrony, or try proportional modes, if suitable; consider paralyzing agents if } \\
\text { tidal volume is too high ( }>8 \mathrm{~mL} / \mathrm{kg} \text { ideal body weight) in patients with ARDS or those } \\
\text { with risk factors for lung injury. }\end{array}$ \\
\hline Double-triggering due to reverse-triggering & $\begin{array}{l}\text { Decrease sedation if clinically suitable; check breathing frequency; consider paralyzing } \\
\text { agents if tidal volume is too high }(>8 \mathrm{~mL} / \mathrm{kg} \text { ideal body weight) in patients with ARDS } \\
\text { or those with risk factors for lung injury. }\end{array}$ \\
\hline Ineffective inspiratory efforts & $\begin{array}{l}\text { Check trigger sensitivity and excessive air-trapping; check for excessive assistance } \\
\text { (excessive set frequency or inspiratory time during controlled modes, or excessive pressure } \\
\text { support ventilation level), counterbalance intrinsic PEEP by using external PEEP; check } \\
\text { for dyspnea; if suitable, try proportional modes. }\end{array}$ \\
\hline Expiratory muscle contraction during expiration & Check for excessive assistance; check for air-trapping and intrinsic PEEP. \\
\hline
\end{tabular}

$\overline{\text { Adapted from Reference }}$ 10, with permission.

of double-triggering as $\geq 10 \%$ double-triggered breaths within a 3 -min period, de Haro et $\mathrm{al}^{44}$ reported that $59.7 \%$ of subjects had clusters, with a median of 6 cluster events per subjects and 41 double-triggered breaths per cluster. Defining clusters of IE as $>30$ IEs in a 3-min period, Vaporidi et $\mathrm{al}^{81}$ observed that clusters were associated with increased risk of remaining on mechanical ventilation for $>$ $8 \mathrm{~d}$ after the first recording and with increased risk of dying in the hospital. Moreover, other cluster characteristics, such as power and duration, also correlated with the duration of mechanical ventilation after the first recording, suggesting that the intensity of the clusters in a given time frame might be more important for outcomes than the general presence of asynchronies. In line with this hypothesis, using Bayesian joint models to assess the association between repeatedly measured variables (ie, SOFA and asynchrony index) and time-to-event data in a cohort of 139 mechanically ventilated subjects, Rué et al ${ }^{123}$ reported a strong relationship between SOFA and vital status, but there was not enough evidence to conclude that asynchronies provide a more accurate indication of death prognosis than SOFA score alone (Fig. 11).

Moreover, it is likely that asynchronies occurring early during mechanical ventilation when patients are ventilated 

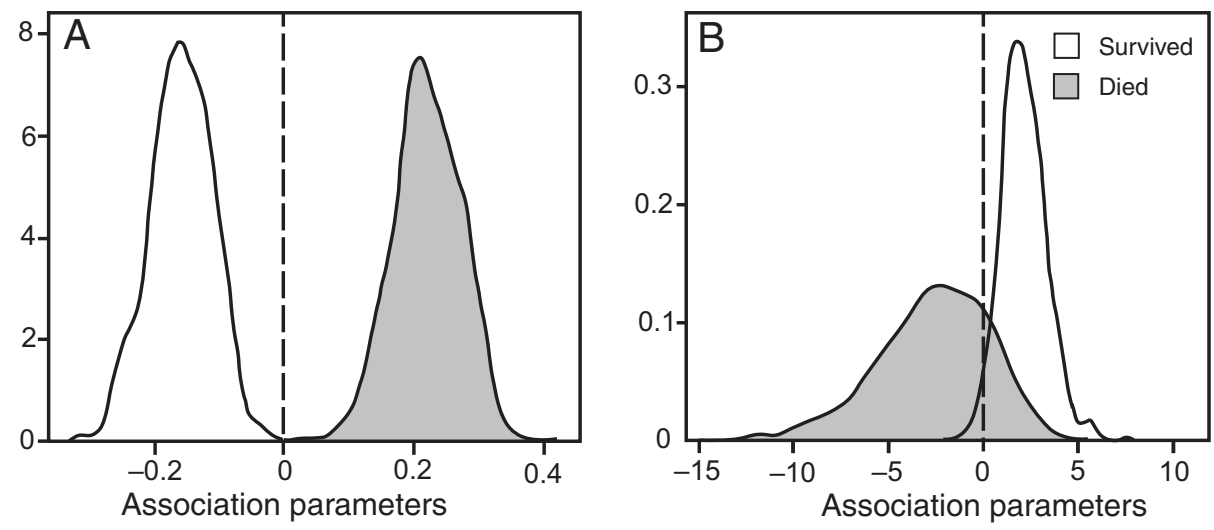

Fig. 11. Analysis of the mixed effects of SOFA score and asynchrony index in ICU survival at ICU using a Bayesian joint model of bivariate longitudinal and competing risks data. SOFA score is strongly related with survival status at ICU discharge. The distributions do not overlap, indicating strong association of the SOFA score with respect to vital status. In contrast, asynchrony index at time $t$ does not seem to be associated with vital status as clearly when overall severity is taken into account. For the event Survived, the asynchrony index has a positive support, indicating that patient-ventilator interactions could be a sign of good prognosis. For the event Died, the asynchrony index parameter indicates that patient-ventilator interactions at time $t$ do not provide a more accurate indication of death prognosis than the SOFA score alone. From Reference 123, with permission.

with control modes have a different impact than those that occur during partial ventilatory support or during periods of liberation from mechanical ventilation. Therefore, to better understand the influence of different asynchronies on ICU and hospital outcomes, further studies should assess how they present (ie, clusters, intensity) and when they occur.

\section{Future Directions}

Recent definitions of personalized medicine consider physiological variables to be essential biomarkers in critical care because they are closely related to physiological recovery and organ support. ${ }^{124,125}$ Precision critical care medicine begins with real-time evaluation of continuously recorded physiological variables, which provides valuable information about the patient's current and dynamic risk profiles. ${ }^{10}$

Smart systems capable of automatically recording and evaluating physiological data in real time to improve the quality, safety, and efficacy of medical decisions are of great interest. ${ }^{126,127}$ These systems must ensure that all relevant data are recorded and that information is intelligently filtered and presented appropriately. ${ }^{127}$ To enable individualized assessment using physiological biomarkers to predict whether a particular patient is likely to experience an adverse event, systems must be capable of automatically transforming raw data into useful information and presenting it in integrated displays showing the information that is most relevant for clinical decision making. ${ }^{124,127-129}$ Alert thresholds derived from continuous predictive analytical monitoring can be operationalized as a degree of change from the patient's own baseline rather than from arbitrary cutoffs. ${ }^{130}$
To develop smart alarms, artificial intelligence can incorporate multiple datasets, including demographics, mechanical ventilation data, and medical texts (structured or unstructured). Smart alarms derived from monitoring asynchronies during mechanical ventilation promise to facilitate decision making, optimize patient-ventilator interaction, decrease morbidity and mortality, and improve quality of life. ${ }^{10,19,107}$

Exploiting the vast quantities of data generated in health care will change medical care, enriching physician-patient relationships with insights from machine learning. ${ }^{131}$ Furthermore, time-series forecasting aims to predict future events on the basis of past observations. The Hidden Markov model is a statistical approach applied in data analysis to recognize patterns over time, and sequential data could be presented as a Markov chain of latent (or hidden) states. Recently, Marchuk et $\mathrm{al}^{132}$ reported the feasibility of Hidden Markov models to predict periods with high frequencies of asynchrony events. Importantly, this model could be used to create an alarm system that could predict the likelihood of asynchrony events and alert care providers. In addition to big data techniques, new approaches such as deep machine learning, artificial neural networks, and entropy and complexity analysis techniques will help clinicians better select patients who might benefit from disconnection from mechanical ventilation.

Recently, Tobin wrote, "Over the breadth of my pulmonary and critical care practice, no area demands greater understanding of physiological principles than ventilator management." ${ }^{24}$ We agree completely: the more accurate our comprehension of patient-ventilator interactions, the 


\section{Monitoring Asynchrony During InVasive Mechanical Ventilation}

greater the benefit for our patients and for future technological developments. Although it is still hard to imagine that technology could replicate tasks or expert thinking that require human intelligence for the complex management of critically ill patients receiving mechanical ventilation, great progress is being made in that direction. Experience will always be valuable, but the future will be better for patients, families, and clinicians.

\section{ACKNOWLEDGMENTS}

We thank John Giba for editing the manuscript.

\section{REFERENCES}

1. Georgopoulos D, Roussos C. Control of breathing in mechanically ventilated patients. Eur Respir J 1996;9(10):2151-2160.

2. Georgopoulos D. Effects of mechanical ventilation on control of breathing. In: Tobin MJ, ed. Principles and Practice of Mechanical Ventilation, 3e. New York: McGraw-Hill; 2013:805-820.

3. Tobin MJ. Advances in mechanical ventilation. N Engl J Med 2001;344(26):1986-1996.

4. Blanch L, Villagra A, Sales B, Montanya J, Lucangelo U, Luján M, et al. Asynchronies during mechanical ventilation are associated with mortality. Intensive Care Med 2015;41(4):633-641.

5. Telias I, Brochard L, Goligher EC. Is my patient's respiratory drive (too) high? Intensive Care Med 2018;44(11):1936-1939.

6. Pham T, Telias I, Piraino T, Yoshida T, Brochard LJ. Asynchrony consequences and management. Crit Care Clin 2018;34(3):325-341.

7. Branson RD, Blakeman TC, Robinson BR. Asynchrony and dyspnea. Respir Care 2013;58(6):973-989.

8. Kavanagh BP, Slutsky AS. Ventilator-induced lung injury: more studies, more questions. Crit Care Med 1999;27:1666-1671.

9. Aquino Esperanza J, Sarlabous L, de Haro C, Batlle M, Magrans R, Lopez-Aguilar J, et al. Double and multiple cycling in mechanical ventilation: complex events with varying clinical effects. Med Intensiva 2019 [Epub ahead of print].

10. Subirà $\mathrm{C}$, de Haro $\mathrm{C}$, Magrans R, Fernández R, Blanch L. Minimizing asynchronies in mechanical ventilation: current and future trends. Respir Care 2018;63(4):464-478.

11. de Wit M. Monitoring of patient-ventilator interaction at the bedside. Respir Care 2011;56(1):61-72.

12. Gilstrap D, MacIntyre N. Patient-ventilator interactions implications for clinical management. Am J Respir Crit Care Med 2013;188 (9): 1058-1068.

13. Vaporidi K, Akoumianaki E, Telias I, Goligher EC, Brochard L, Georgopoulos D. Respiratory drive in critically ill patients: pathophysiology and clinical implications. Am J Respir Crit Care Med 2020;201(1):20-32.

14. Yoshida T, Fujino Y, Amato MBP, Kavanagh BP. Fifty years of research in ARDS spontaneous breathing during mechanical ventilation risks, mechanisms, and management. Am J Respir Crit Care Med 2017;195(8):985-992.

15. Levine S, Nguyen T, Taylor N, Friscia M, Budak MT, Rothenberg P, et al. Rapid disuse atrophy of diaphragm fibers in mechanically ventilated humans. N Engl J Med 2008;358(13):1327-1335.

16. Putensen C, Zech S, Wrigge H, Zinserling J, Stüber F, Von ST, et al. Long-term effects of spontaneous breathing during ventilatory support in patients with acute lung injury. Am J Respir Crit Care Med 2001;164(1):43-49.

17. Yoshida $\mathrm{T}$, Uchiyama A, Matsuura N, Mashimo $\mathrm{T}$, Fujino $\mathrm{Y}$. Spontaneous breathing during lung-protective ventilation in an experimental acute lung injury model: high transpulmonary pressure associated with strong spontaneous breathing effort may worsen lung injury. Crit Care Med 2012;40(5):1578-1585.

18. Yoshida T, Roldan R, Beraldo MA, Torsani V, Gomes S, De Santis $\mathrm{RR}$, et al. Spontaneous effort during mechanical ventilation: maximal injury with less positive end-expiratory pressure. Crit Care Med 2016;44(8):e678-88.

19. Brochard L, Martin GS, Blanch L, Pelosi P, Belda FJ, Jubran A, et al. Clinical review: respiratory monitoring in the ICU - a consensus of 16. Crit Care 2012;16(2):219.

20. Dres M, Goligher EC, Heunks LMA, Brochard LJ. Critical illnessassociated diaphragm weakness. Intensive Care Med 2017;43 (10): 1441-1452.

21. Papazian L, Forel J-M, Gacouin A, Penot-Ragon C, Perrin G, Loundou A, et al. Neuromuscular blockers in early acute respiratory distress syndrome. N Engl J Med 2010;363(12):1107-1116.

22. Doorduin J, Nollet JL, Roesthuis LH, Hees HWH, Van rochard LJ, Sinderby CA, et al. Partial neuromuscular blockade during partial ventilatory support in sedated patients with high tidal volumes. Am J Respir Crit Care Med 2017;195(8):1033-1042.

23. Morais CC, Koyama Y, Yoshida T, Plens G, Gomes S, Lima CL, et al. High positive end-expiratory pressure renders spontaneous effort non-injurious. Am J Respir Crit Care Med 2018;197(10):12851296.

24. Tobin MJ. Physiologic basis of mechanical ventilation. Ann Am Thorac Soc 2018;15(Suppl 1):S49-S52.

25. de Haro C, Ochagavia A, López-Aguilar J, Fernandez-Gonzalo S, Navarra-Ventura G, Magrans R, et al. Patient-ventilator asynchronies during mechanical ventilation: current knowledge and research priorities. Intensive Care Med Exp 2019;7(S1):1-14.

26. Murias G, Lucangelo U, Blanch L. Patient-ventilator asynchrony. Curr Opin Crit Care 2016;22(1):53-59.

27. Ward M, Corbeil C, Gibbons W, Newman S, Macklem P. Optimization of respiratory muscle relaxation during mechanical ventialtion. Anestesiology 1988;69:29-35.

28. Cinnella G, Conti G, Lofaso F, Lorino H, Harf A, Lemaire OIS, et al. Effects of assisted ventilation on the work of breathing volume-controlled versus pressure-controlled ventilation. Am J Respir Crit Care Med 1996;153(3): 1025-1033.

29. MacIntyre NR, McConnell R, Cheng K, Sane A. Patient-ventilator flow dyssynchrony: flow-limited versus pressure-limited breaths. Crit Care Med 1997;25:161-167.

30. Banzett RB, Schwartzstein RM. Dyspnea: don't just look, ask. Am J Respir Crit Care Med 2015;192(12):1404-1406.

31. Schmidt M, Banzett RB, Raux M, Morélot-Panzini C, Dangers L, Similowski T, Demoule A. Unrecognized suffering in the ICU: addressing dyspnea in mechanically ventilated patients. Intensive Care Med 2014;40(1):1-10.

32. Parshall MB, Schwartzstein RM, Adams L, Banzett RB, Manning HL, Bourbeau J, et al. An official American thoracic society statement: update on the mechanisms, assessment, and management of dyspnea. Am J Respir Crit Care Med 2012;185(4):435-452.

33. Soffler MI, Rose A, Hayes MM, Banzett R, Schwartzstein RM. Treatment of acute dyspnea with morphine to avert respiratory failure. Ann Am Thorac Soc 2017;14(4):584-588.

34. Schmidt M, Demoule A, Polito A, Porchet R, Aboab J, Siami S, et al. Dyspnea in mechanically ventilated critically ill patients. Crit Care Med 2011;39(9):2059-2065.

35. Haugdahl HS, Storli SL, Meland B, Dybwik K, Romild U, Klepstad P. Underestimation of patient breathlessness by nurses and physicians during a spontaneous breathing trial. Am J Respir Crit Care Med 2015;192(12):1440-1448. 


\section{Monitoring Asynchrony During InVasive Mechanical Ventilation}

36. Decavèle M, Similowski T, Demoule A. Detection and management of dyspnea in mechanically ventilated patients. Curr Opin Crit Care 2019;25(1):86-94.

37. Quilez ME, Fuster G, Villar J, Flores C, Martí-Sistac O, Blanch L, et al. Injurious mechanical ventilation affects neuronal activation in ventilated rats. Crit Care 2011;15(3):R124.

38. Bilotta F, Giordano G, Sergi PG, Pugliese F. Harmful effects of mechanical ventilation on neurocognitive functions. Crit Care 2019;23 (1):273.

39. Evans J, Sumners C, Moore J, Huentelman MJ, Deng J, Gelband CH, et al. Characterization of mitotic neurons derived from adult rat hypothalamus and brain stem. J Neurophysiol 2002;87(2):1076-1085.

40. Blanch L, Quintel M. Lung-brain cross talk in the critically ill. Intensive Care Med 2017;43(4):557-559.

41. Quílez ME, López-Aguilar J, Blanch L. Organ crosstalk during acute lung injury, acute respiratory distress syndrome, and mechanical ventilation. Curr Opin Crit Care 2012;18(1):23-28.

42. Thille AW, Rodriguez P, Cabello B, Lellouche F, Brochard L. Patient-ventilator asynchrony during assisted mechanical ventilation. Intensive Care Med 2006;32(10):1515-1522.

43. Beitler JR, Sands SA, Loring SH, Owens RL, Malhotra A, Spragg $\mathrm{RG}$, et al. Quantifying unintended exposure to high tidal volumes from breath stacking dyssynchrony in ARDS: the BREATHE criteria. Intensive Care Med 2016;42(9):1427-1436.

44. de Haro C, López-Aguilar J, Magrans R, Montanya J, FernándezGonzalo S, Turon M, et al. Double cycling during mechanical ventilation: frequency, mechanisms, and physiological implications. Crit Care Med 2018;46(9):1385-1392.

45. Thille AW, Cabello B, Galia F, Lyazidi A, Brochard L. Reduction of patient-ventilator asynchrony by reducing tidal volume during pressure-support ventilation. Intensive Care Med 2008;34(8):1477-1486.

46. Pohlman MC, McCallister KE, Schweickert WD, Pohlman AS, Nigos CP, Krishnan JA, et al. Excessive tidal volume from breath stacking during lung-protective ventilation for acute lung injury. Crit Care Med 2008;36(11):3019-3023.

47. Goligher EC. Myotrauma in mechanically ventilated patients. Intensive Care Med 2019;45(6):881-884.

48. Goligher EC, Fan E, Herridge MS, Murray A, Vorona S, Brace D, et al. Evolution of diaphragm thickness during mechanical ventilation: impact of inspiratory effort. Am J Respir Crit Care Med 2015;192(9):1080-1088.

49. Gea J, Zhu E, Gáldiz JB, Comtois N, Salazkin I, Antonio Fiz J, et al. Functional consequences of eccentric contractions of the diaphragm. Arch Bronconeumol 2009;45(2):68-74.

50. Chanques G, Kress J, Pohlman A, Patel S, Poston J, Jaber S, et al. Impact of ventilator adjustement and sedation-analgesia practices on severe asynchrony in patients ventilated in assist-control mode. Crit Care Med 2013;41:2177-2187.

51. Vitacca M, Bianchi L, Zanotti E, Vianello A, Barbano L, Porta R, et al. Assessment of physiologic variables and subjective comfort under different levels of pressure support ventilation. Chest 2004;126 (3):851-859.

52. Tassaux D, Gainnier M, Battisti A, Jolliet P. Impact of expiratory trigger setting on delayed cycling and inspiratory muscle workload. Am J Respir Crit Care Med 2005;172(10):1283-1289.

53. Leung P, Jubran A, Tobin MJ. Comparison of assisted ventilator modes on triggering, patient effort, and dyspnea. Am J Respir Crit Care Med 1997;155(6):1940-1948.

54. Parthasarathy S, Jubran A, Tobin MJ. Cycling of inspiratory and expiratory muscle groups with the ventilator in airflow limitation. Am J Respir Crit Care Med 1998;158(5):1471-1478.

55. Brochard L. Intrinsic (or auto-) positive end-expiratory pressure during spontaneous or assisted ventilation. Intensive Care Med 2002;28 (11):1552-1554.
56. Vaschetto R, Cammarota G, Colombo D, Longhini F, Grossi F, Giovanniello A, et al. Effects of propofol on patient-ventilator synchrony and interaction during pressure support ventilation and neurally adjusted ventilatory assist. Crit Care Med 2014;42(1):74-82.

57. de Wit M, Pedram S, Best AM, Epstein SK. Observational study of patient-ventilator asynchrony and relationship to sedation level. J Crit Care 2009;24(1):74-80.

58. Parthasarathy S, Jubran A, Laghi F, Tobin MJ. Sternomastoid, rib cage, and expiratory muscle activity during weaning failure. J Appl Physiol 2007;103(1):140-147.

59. Fernandez R, Mendez M, Younes M. Effect of ventilator flow rate on respiratory timing in normal humans. 1999;159:710-719.

60. Gilstrap D, Davies J. Patient-Ventilator Interactions. Clin Chest Med 2016;37(4):669-681.

61. Shi ZH, Jonkman A, de Vries H, Jansen D, Ottenheijm C, Girbes A, et al. Expiratory muscle dysfunction in critically ill patients: towards improved understanding. Intensive Care Med 2019;45(8):1061-1071.

62. Doorduin J, Roesthuis LH, Jansen D, Van Der Hoeven JG, van Hees HWH, Heunks LMA, et al. Respiratory Muscle Effort during Expiration in successful and failed weaning from mechanical ventilaton. Anesthesiology 2018;129(3):490-501.

63. Petrillo G, Glass L. A theory for phase locking of respiration in cats to a mechanical ventilator. Am J Physiol 1984;246(3 Part 2):311320.

64. Muzzin S, Trippenbach T, Baconnier P, Benchetrit G. Entrainment of the respiratory rhythm by periodic lung inflation during vagal cooling. 1989;75:157-172.

65. Muzzin S, Baconnier P, Benchetrit G. Entrainment of respiratory rhythm by periodic inflation: effect of airflow rate and duration. Am J Physiol 1992:292-300.

66. Petrillo G, Glass L, Trippenbach T. Phase locking of the respiratory rhythm in cats to a mechanical ventilator. Can J Physiol Pharmacol 1983;61(6):599-607.

67. Simon P M, Zurob A S, Wies W M, Leiter J C, Hubmayr R D, Jensen M L, et al. Entrainment of respiration in humans by periodic lung inflations: effect of state and CO2. Am J Respir Crit Care Med 1999;160(3):950-960.

68. Simon PM, Habel AM, Daubenspeck JA, Leiter JC, PM, Habel AM, et al. Vagal feedback in the entrainment of respiration to mechanical ventilation in sleeping humans. J Appl Physiol 2000;89(2):760-769.

69. Delisle S, Charbonney E, Albert M, Ouellet P, Marsolais P, Rigollot $\mathrm{M}$, et al. Patient-ventilator asynchrony due to reverse triggering occurring in brain-dead patients: clinical implications and physiological meaning. Am J Respir Crit Care Med 2016;194(9):1166-1168.

70. Akoumianaki E, Lyazidi A, Rey N, Matamis D, Perez-Martinez N, Giraud R, et al. Mechanical ventilation-induced reverse-triggered breaths: a frequently unrecognized form of neuromechanical coupling. Chest 2013;143(4):927-938.

71. de Vries HJ, Jonkman AH, Tuinman PR, Girbes ARJ, Heunks L. Respiratory entrainment and reverse triggering in a mechanically ventilated patient. Ann Am Thorac Soc 2019;16(4):499-505.

72. Murias G, de Haro C, Blanch L. Does this ventilated patient have asynchronies? Recognizing reverse triggering and entrainment at the bedside. Intensive Care Med 2016;42(6):1058-1061.

73. Pham T, Montanya J, Piraino T, Magrans Nicieza R, Mellado Artigas $\mathrm{R}$, Damiani F, et al. Reverse triggering during invasive mechanical ventilation: validation of an automatic detection software [abstract]. Presented at the 2019 ATS International Conference. 2019. doi: 10.1164/ajrccm-conference.2019.199.1_MeetingAbstracts.A4253.

74. Su HK, Loring SH, Talmor D, Kassis EB. Reverse triggering with breath stacking during mechanical ventilation results in large tidal volumes and transpulmonary pressure swings. Intensive Care Med 2019;45(8):1161-1162. 


\section{Monitoring Asynchrony During InVasive Mechanical Ventilation}

75. Yoshida T, Nakamura MAM, Morais CCA, Amato MBP, Kavanagh BP. Reverse triggering causes an injurious inflation pattern during mechanical ventilation. Am J Respir Crit Care Med 2018;198 (8):1096-1099.

76. Kallet RH, Campbell AR, Dicker RA, Katz JA, Mackersie RC. Effects of tidal volume on work of breathing during lung-protective ventilation in patients with acute lung injury and acute respiratory distress syndrome. Crit Care Med 2006;34(1):8-14.

77. Chacon E, Estruga A, Murias G, Sales B, Montanya J, Lucangelo U, et al. Nurses' detection of ineffective inspiratory efforts during mechanical ventilation. Am J Crit Care 2012;21(4):89-94.

78. Akoumianaki E, Maggiore SM, Valenza F, Bellani G, Jubran A, Loring $\mathrm{SH}$, et al. The application of esophageal pressure measurement in patients with respiratory failure. Am J Respir Crit Care Med 2014;189(5):520-531.

79. Yoshida T, Amato MBP, Grieco DL, Chen L, Lima CAS, Roldan R, et al. Esophageal manometry and regional transpulmonary pressure in lung injury. Am J Respir Crit Care Med 2018;197(8):1018-1026.

80. Rolland-Debord C, Bureau C, Poitou T, Belin L, Clavel M, Perbet S, et al. Prevalence and prognosis impact of patient - ventilator asynchrony in early phase of weaning according to two detection methods. Anesthesiology 2017;127:989-997.

81. Vaporidi K, Babalis D, Chytas A, Lilitsis E, Kondili E, Amargianitakis V, et al. Clusters of ineffective efforts during mechanical ventilation: impact on outcome. Intensive Care Med 2017;43(2):184-191.

82. Sottile PD, Albers D, Higgins C, Mckeehan J, Moss MM. The association between ventilator dyssynchrony, delivered tidal volume, and sedation using a novel automated ventilator dyssynchrony detection algorithm. Crit Care Med 2018;46(2):e151-e157.

83. Blanch L, Sales B, Montanya J, Lucangelo U, Oscar GE, Villagra A, et al. Validation of the Bette Care system to detect ineffective efforts during expiration in mechanically ventilated patients: a pilot study. Intensive Care Med 2012;38(5):772-780.

84. Adams JY, Lieng MK, Kuhn BT, Rehm GB, Guo EC, Taylor SL, et al. Development and validation of a multi-algorithm analytic platform to detect off-target mechanical ventilation. Sci Rep 2017;7 (1): 14980.

85. Gutierrez G, Ballarino GJ, Turkan H, Abril J, De La Cruz L, Edsall $\mathrm{C}$, et al. Automatic detection of patient-ventilator asynchrony by spectral analysis of airway flow. Crit Care 2011;15(4):R167.

86. Aurell J, Elmqvist D. Sleep in the surgical intensive care unit: continuous polygraphic recording of sleep in nine patients receiving postoperative care. Br Med J (Clin Res Ed) 1985;290(6474):1029-1032.

87. Cooper AB, Thornley KS, Young GB, Slutsky AS, Stewart TE, Hanly PJ. Sleep in critically ill patients requiring mechanical ventilation. Chest 2000;117(3):809-818.

88. Richards K, Brainsfather L. A description of night sleep patterns in the critical care unit. Hear Lung 1988;17:35-42.

89. Broughton R, Baron R. Sleep patterns in the intensive care unit and on the ward after acute myocardial infarction. Electroencephalogr Clin Neurophysiol 1978;45(3):348-360.

90. Freedman NS, Gazendam J, Levan L, Pack AI, Schwab RJ. Abnormal sleep/wake cycles and the effect of environmental noise on sleep disruption in the intensive care unit. Am J Respir Crit Care Med 2001;163(2):451-457.

91. Weinhouse GL, Schwab RJ. Sleep in the critically ill patient. Sleep 2006;29(5):707-716.

92. Cabello B, Parthasarathy S, Mancebo J. Mechanical ventilation: let us minimize sleep disturbances. Curr Opin Crit Care 2007;13:20-26.

93. Trompeo A, Vidi Y, Locane M, Braghiroli A, MAscia L, Bosma K, et al. Sleep disturbances in the critically ill patients: role of delirium and sedative agents. Minerva Anestesiol 2011;77(6):604-612.
94. Younes M. To sleep: perchance to ditch the ventilator. Eur Respir J 2018;51(4):1800624.

95. Pisani MA, Friese RS, Gehlbach BK, Schwab RJ, Weinhouse GL, Jones SF. Sleep in the intensive care unit. Am J Respir Crit Care Med 2015;191(7):731-738

96. Meza S, Mendez M, Ostrowski M, Younes M. Susceptibility to periodic breathing with assisted ventilation during sleep in normal subjects. J Appl Physiol 1998;85(5):1929-1940.

97. Parthasarathy S, Tobin MJ. Effect of ventilator mode on sleep quality in critically ill patients. Am J Respir Crit Care Med 2002;166 (11):1423-1429.

98. Thille AW, Reynaud F, Marie D, Barrau S, Rousseau L, Rault C, et al. Impact of sleep alterations on weaning duration in mechanically ventilated patients: a prospective study. Eur Respir J 2018;51 (4): 1702465.

99. Alexopoulou C, Kondili E, Plataki M, Georgopoulos D. Patient-ventilator synchrony and sleep quality with proportional assist and pressure support ventilation. Intensive Care Med 2013;39(6):1040-1047.

100. Bosma K, Ferreyra G, Ambrogio C, Pasero D, Mirabella L, Braghiroli A, et al. Patient-ventilator interaction and sleep in mechanically ventilated patients: pressure support versus proportional assist ventilation. Crit Care Med 2007;35(4):1048-1054.

101. Delisle S, Ouellet P, Bellemare P, Tétrault J, Arsenault P. Sleep quality in mechanically ventilated patients: comparison between NAVA and PSV modes. Ann Intensive Care 2011:1-8.

102. Cunningham D, Robbins P, Wolf C. Integration of respiratory response to changes in alveolar partial pressure of $\mathrm{CO} 2$ and $\mathrm{O} 2$ and in the arterial $\mathrm{pH}$. In: Cherniack $\mathrm{N}$, Widdicombe J, editors. Handbook of physiology: the respiratory system, vol 2. Rockville, MD: American Physiological Society; 1986:475-528.

103. Coleridge H, Coleridge J. Reflexes evoked from tracheobronchial tree and lungs. In: Cherniack N, Widdicombe J, editors. Handbook of physiology: the respiratory system, vol 2. Rockville, MD: American Physiological Society; 1986:395-430.

104. Shannon R. Reflexes evoked from respiratory muscles and cortovertebral joint. In: Cherniack N, Widdicombe J, editors. Handbook of physiology: the respiratory system, vol 2. Rockville, MD: American Physiological Society; 1986:431-438.

105. Hansen-Flaschen JH, Brazinsky S, Basile C, Lanken PN. Use of sedating drugs and neuromuscular blocking agents in patients requiring mechanical ventilation for respiratory failure survey. JAMA 1991;266:2870-2875.

106. Fernandez-Gonzalo S, Turon M, de Haro C, López-Aguilar J, Jodar $\mathrm{M}$, Blanch L. Do sedation and analgesia contribute to long-term cognitive dysfunction in critical care survivors? Med Intensiva 2018;42 (2):114-128.

107. Jarman AM, Duke GJ, Reade MC, Casamento A. The association between sedation practices and duration of mechanical ventilation in intensive care. Anaesth Intensive Care 2013;41(3):311-315.

108. Shehabi Y, Chan L, Kadiman S, Alias A, Ismail W, Ismail Tan M, et al. Sedation depth and long-term mortality in mechanically ventilated critically ill adults: a prospective longitudinal multicentre cohort study. Intensive Care Med 2013;39(5):910-918.

109. Barr J, Fraser GL, Puntillo K, Ely EW, Gélinas C, Dasta JF, et al. Clinical practice guidelines for the management of pain, agitation, and delirium in adult patients in the intensive care unit: executive summary. Am J Heal Pharm 2013;70(1):53-58.

110. Patel SP, Kress JP. Sedation and analgesia in the mechanically ventilated patient. Am J Respir Crit Care Med 2012;185(5):486-497.

111. Kress JP, Pohlman AS, O'Connor MF, Hall JB. Daily interruption of sedatives infusions in critically ill patients undergoing mechanical ventilation. N Engl J Med 2000;342(20):1471-1477.

112. Devlin JW, Skrobik Y, Vice-Chair F, Gélinas C, Needham DM, Slooter AJC. Clinical practice guidelines for the prevention and 


\section{Monitoring Asynchrony During InVasive Mechanical Ventilation}

management of pain, agitation/sedation, delirium, immobility, and sleep disruption in adult patients in the ICU. Crit Care Med 2018;46:825-873.

113. de Haro C, Magrans R, López-Aguilar J, Montanyà J, Lena E, Subirà $\mathrm{C}$, et al. Effects of sedatives and opioids on trigger and cycling asynchronies throughout mechanical ventilation: an observational study in a large dataset from critically ill patients. Crit Care 2019;23(1):245.

114. Laghi F, Karamchandani K, Tobin MJ. Influence of ventilator settings in determining respiratory frequency during mechanical ventilation. Am J Respir Crit Care Med 1999;160(5):1766-1770.

115. Xirouchaki N, Kondili E, Vaporidi K, Xirouchakis G, Klimathianaki M, Gavriilidis G, et al. Proportional assist ventilation with load-adjustable gain factors in critically ill patients: comparison with pressure support. Intensive Care Med 2008;34(11):2026-2034.

116. Costa R, Spinazzola G, Cipriani F, Ferrone G, Festa O, Arcangeli A, et al. A physiologic comparison of proportional assist ventilation with load-adjustable gain factors $(\mathrm{PAV}+)$ versus pressure support ventilation (PSV). Intensive Care Med 2011;37(9):1494-1500.

117. Vasconcelos RS, Sales RP, Melo LHP, Marinho LS, Bastos VP, Nogueira ADN, et al. Influences of duration of inspiratory effort, respiratory mechanics, and ventilator type on asynchrony with pressure support and proportional assist ventilation. Respir Care 2017;62 (5):550-557.

118. Yonis H, Crognier L, Conil J, Serres I, Rouget A, Virtos M, et al. Patient-ventilator synchrony in neurally adjusted ventilatory assist (NAVA) and pressure support ventilation (PSV): a prospective observational study. BMC Anesthesiol 2015;15:117.

119. Di Mussi R, Spadaro S, Mirabella L, Volta CA, Serio G, Staffieri F, et al. Impact of prolonged assisted ventilation on diaphragmatic efficiency: NAVA versus PSV. Crit Care 2016;20:1.

120. Schmidt M, Kindler F, Cecchini J, Poitou T, Morawiec E, Persichini $\mathrm{R}$, et al. Neurally adjusted ventilatory assist and proportional assist ventilation both improve patient-ventilator interaction. Crit Care 2015;19(1):56.

121. Piquilloud L, Vignaux L, Bialais E, Roeseler J, Sottiaux T, Laterre PF, et al. Neurally adjusted ventilatory assist improves patient-ventilator interaction. Intensive Care Med 2011;37(2):263-271.
122. De Wit M, Miller KB, Green DA, Ostman HE, Gennings C, Epstein SK. Ineffective triggering predicts increased duration of mechanical ventilation. Crit Care Med 2009;37(10):2740-2745.

123. Rué M, Andrinopoulou ER, Alvares D, Armero C, Forte A, Blanch L. Bayesian joint modeling of bivariate longitudinal and competing risks data: an application to study patient-ventilator asynchronies in critical care patients. Biom J 2017;59(6):1184-1203.

124. Ince C. Personalized physiological medicine. Crit Care 2017;21 (Suppl 3):308.

125. Suarez-Sipmann F, Blanch L. Physiological markers for acute respiratory distress syndrome: let's get more efficient! Am J Respir Crit Care Med 2019;199(3):260-261

126. Orphanidou C. A review of big data applications of physiological signal data. Biophys Rev 2019;11(1):83-87.

127. De Backere F, Vanhove T, Dejonghe E, Feys M, Herinckx T, Vankelecom J, et al. Platform for efficient switching between multiple devices in the intensive care unit. Methods Inf Med 2015;54(1): 5-15.

128. Triguero I, Garcia-Gil D, Maillo J, Luengo J, Garcia S, Herrera F. Transforming big data into smart data: an insight on the use of the $\mathrm{k}$ nearest neighbors algorithm to obtain quality data. Wires Data Min Knowl Discov 2018:1-24.

129. Koch SH, Weir C, Westenskow D, Gondan M, Agutter J, Haar M, et al. Evaluation of the effect of information integration in displays for ICU nurses on situation awareness and task completion time: a prospective randomized controlled study. Int J Med Inform 2013;82 (8):665-675.

130. Keim-Malpass J, Clark MT, Lake DE, Moorman JR. Towards development of alert thresholds for clinical deterioration using continuous predictive analytics monitoring. J Clin Monit Comput 2019

131. Deo RC. Basic science for clinicians. Circulation 2015;132(20): 1920-1930.

132. Marchuk Y, Magrans R, Sales B, Montanya J, López-Aguilar J, de Haro C, et al. Predicting patient-ventilator asynchronies with hidden Markov models. Sci Rep 2018;8(1):17614.

\section{Discussion}

MacIntyre: It's a little outside the scope of your presentation, but this is something that I keep getting asked all the time. Reverse triggering is obviously very real; if you look for it you'll see it. I fully agree with that. But the obvious question clinicians ask is, "what do I do about it?" With the other asynchronies you can talk about changing sensitivity, changing flow, changing timing, changing this and that but with reverse triggering I don't know what to do. If often occurs in patients who are on high rates and high sedation levels, which are things you might think would reduce asynchronies and yet that's the very milieu in which reverse triggering occurs. Do you have any advice?
Blanch: Well, it's an interesting question. Initially it was thought that reverse triggering happened in patients with ARDS who are heavily sedated in day 1 or day 2 of mechanical ventilation, but now we have observed reverse triggering in patients with sedation and morphine and even awake. Whether the type of drug will make a difference I don't know. Whether reverse trigger is a physiologic phenomenon that has been around for many years and we simply don't understand, I don't know. Which is the best treatment? If you look at Tai's [Pham] paper ${ }^{1}$ on treatment of patients with reverse triggering, you have several options: variations in breathing frequency, try pressure support or treatment with neuromuscular blocking agents in patients at risk of self-inflicted lung injury.
Pham: I totally agree with you that we know very little about this phenomenon at the moment. The first step is to better describe it, and that's why Lluís [Blanch] and his team's work is very important. Because if we can recognize and assess it, we will have a better idea of the main physiological issues. We're continuing the BEARDS study (https://clinicaltrials.gov/ct2/ show/NCT03447288) where we collect data from all kinds of patients from 20 centers across the world. They send us tracings with esophageal pressure, airway pressure, and flow. Now we have 150 subjects and we took a look at the tracings (without proper analysis for the moment) but it seems that patients present reverse triggering at 2 different periods. The first period is when they are in the early phase of ARDS, very 
hypoxemic, sedated, and whatever you do, they still have one on one, one on two reverse triggering, so every other breath will be a reverse triggered breath. Even with heavy sedation. I think at this stage the best treatment is to paralyze because whatever the increase of sedation or you try to tweak the ventilator, they will still display that pattern and maybe have more ventilator associated injury. This is the first period, and the second seems to be when you start decreasing sedation and the patient is not awake enough or not strong enough to trigger all the breaths. The patient cannot lead the machine. The way we differentiate between the two is that we ask all investigators to do a pause. In the first phase you can do a pause of 20 or $30 \mathrm{~s}$ and you will have no underlying effort from the patient. In the second case when you do a pause, at some point you will capture some effort. At this phase the patient has some underlying drive and I don't know if it's that they are lazy or if it's important for them to have the machine trigger the breath before reacting. In a few patients we had in our center, when we witnessed reverse triggering with underlying respiratory drive, we asked the teams if they agreed to try to switch to pressure support or decrease the rate of mechanical ventilation, and the patient started triggering all the breaths.

Piraino: The other issue, and the reason why we need to investigate more, is that, as was mentioned yesterday, we don't know if the type of asynchrony, or when it happens, is the more important aspect. For example, to say that we should paralyze patients who are reverse triggering who are sick may be an overstatement if it's happening only during the inspiratory phase. It may not be as injurious as if it's carrying on later or into the expiratory phase where you start adding eccentric contractions and double breaths. We don't know enough about the mechanism. It's so interesting that the phasing of when it happens is so different with all types of patients that even when we're trying to classify the breaths for research, we reference whether it is reverse triggering into exhalation. We consider when the peak of the effort occurs because when we study these breaths it may have a different mechanism and different potential for injury with different outcomes. It gets very complicated. I agree with Tai, one of the first things we do when we see it is to do an expiratory pause. When you do that pause you'll see patients will just not make any effort. We have had pauses of up to 20 or $30 \mathrm{~s}$ where the patient is doing nothing. In other pauses within $5 \mathrm{~s}$ the patient has a drive and, in those situations, we recommend lowering the frequency if they're not ready for pressure support and have the patient start to drive the ventilator. But it doesn't work if they have no drive, and that's just one quick test to see if they have an underlying drive and they're just entraining to the ventilator.

Schmidt: I have a question about the generalizability of your patients to other patients, because one can imagine that a lot of these asynchronies are dependent on mode, sedative regimes, specific settings, and the culture of how one chooses settings in your particular ICU. So what do you know about patients in other ICUs compared to those in yours?

Blanch: We collected data from 4 ICUs in 4 different hospitals, but differences can occur according to country, different caregivers, like respiratory therapists, intensivists, anesthesiologists, or critical care nurses. In a recent paper, ${ }^{2}$ we found that sedatives, whether alone or combined with opioids, do not result in better patientventilator interaction than opioids alone, in any ventilatory mode. Higher opioid dose (alone or with sedatives) was associated with lower asynchrony index without depressing consciousness, independent of the MV mode. Moreover, dedicated software can help to detect patient-ventilator asynchrony alerting professionals to detect patients entering in high-risk state. ${ }^{3}$ I have conflict of interest on these developments, but software to improve asynchronies detection should be implemented in ICUs to improve quality.

Goligher: Lluís, thanks for a very compelling presentation. How useful is the asynchrony index given that all of these different types of asynchronies are really very different phenomena with different pathophysiological significance? As time goes on it strikes me more and more that it's very odd the way we lump them all together and report asynchrony index.

Blanch: We compute our asynchrony index according to Thille et $\mathrm{al},{ }^{4}$ which considers prolonged cycling, short cycling, double triggering, and ineffective efforts. I agree that lumping together all these asynchronies has difficulties to identify physiologic differences between asynchronies. Moreover, asynchronies might present in clusters suggesting that intensity could be more important than the mere presence of them. In fact, Vaporidi et $\mathrm{al}^{5}$ found an association of clusters of ineffective efforts with increased hospital mortality.

Goligher: It strikes me that we need to move past this index, and it's completely understandable that we've reported asynchrony index in the past, but I think that as we learn more and more about the different significance we need to move beyond some parameter that incorporates them and lumps them all together.

Blanch: We are thinking how to do that. In fact, we are building abig database to construct different approximations of asynchronies. I 
was astonished when we found that some asynchronies maybe indicate that the patient is going to live. ${ }^{6}$ So that's why we need other forms to study asynchronies.

Piraino: It does seem like the software is now distinguishing every different type of asynchrony, so even if you report on the one screen an asynchrony index at the top, but below it was separated so you have the ability to distinguish individual asynchronies. I like how you circled the patient that had a large number of double triggering and then reverse triggering events, at least now you can distinguish individual types from the total percentage of the breaths.

Blanch: We are actually trying to assess this in a database in general ICU patients, not only ARDS. To me, we are focusing too much on ARDS. ARDS happens in what, $5 \%$ of patients in the ICU? When you look at mortality, around $30 \%$ of all mechanically ventilated patients die. That's why we need data in all ICU patients receiving mechanical ventilation.

Branson: Lluís, just as a clinical person at the bedside, do you think that clusters are associated with events like patient movement, procedures at the bedside, and changes in sedation? Or do they just de novo occur?

Blanch: My clinical thinking is that you are totally right. If you move the patient and there is pain maybe the patient gets dyspnea, or needs another type of ventilator support, probably yes. We have found that opioid dose (alone or with sedatives) was associated with lower asynchrony index without depressing consciousness independent of the mechanical ventilator mode. ${ }^{2}$ Maybe we need to change our practices.

Walsh: One of the questions I have for you as an expert in asynchronies, is do patients tend to have one majority asynchrony? And then is there a way to relate that to outcome? In other words, at this point in time is there a lethal asynchrony like we have for arrhythmias, or some that are just painful but don't contribute to a prolonged mechanical ventilation course?

Blanch: According to previous investigations from many groups, the most frequent asynchrony is ineffective effort. However, reverse triggering or phase asynchronies are more frequent than we think. We need more research on this topic. The importance of these on outcomes? I don't know, but we should keep in mind that studies comparing pressure support with PAV or NAVA, none of them have shown an influence on prognosis or early weaning using modes that perfectly synchronize the start of each inspiration and the transition from inspiration to expiration. So, maybe the important asynchronies as we discussed yesterday are the ones that can affect the integrity of the lung or diaphragm injury.

Pham: I like your comparison with cardiac arrhythmia; I think it's very similar though we don't have proof yet. There might be asynchrony where there is nothing to do about it and some that are injurious to the diaphragm or the lungs. Again, we need to be able to describe and then see what is the impact of each of them on outcomes.

Walsh: I was just wondering if there was a patient population that you could pull out that have a certain type of asynchrony over another, or is it evenly distributed that when they have asynchronies they have all types of asynchronies with primarily ineffective trigger? As we explore more and more patients and add them to your dataset, do you think you could pull those out and start to obtain whether length of ventilation is a problem in that particular asynchrony or mortality in another?

Blanch: I strongly believe we need advanced computing to identify asynchronies when we are not at the bedside. We need to look associations of asynchronies and the intensity of these associations and use advanced analytics. To me, the future is the full and continuous analysis of ventilator waveforms to answer this particular question.

Goligher: I think we really have to be very cautious about drawing inferences about the causal significance of associations between asynchronies and clinical outcomes because there's such a strong relationship between severity of disease and risk of asynchrony. With ineffective efforts, if you have more severe airway obstruction you're more likely to have ineffective efforts. Really the only way to tease out the true clinical significance of these things is to design trials where you're intervening on the asynchrony. For example, the fact that neuromuscular blockade doesn't seem to significantly impact outcome in ARDS raises the question of whether reverse triggering is that big of a deal in early ARDS. I think while we're still waiting for what will be some very interesting physiological data looking at the question, it's such a difficult area to study because the confounding is a massive, massive problem.

Blanch: I think you are totally correct. Maybe we need this type of information. We need to look and interpret real ICU world data, i.e, all data, all time. So, I am curious on real world ICU data because it opens minds in many aspects and can help to design more specific RCTs. That's why, and again I repeat, respiratory physiology is of paramount importance at bedside, but computers could help.

Walsh: I'm obviously in support of RCTs but I think the day of big data, 


\section{Monitoring Asynchrony During InVasive Mechanical Ventilation}

and Craig [Smallwood] may get to some of this, if we can connect our ICUs and create these huge databases, then RCTs may not be the most efficient way to go to actually tease out some of the responses we want to get out of it.

Goligher: Personally, I respectfully disagree, to be honest. The RCT is the only way to deal with unobserved and unobservable confounding in these kinds of datasets. Particularly with big data, and I have a lot to learn in this area, but where you pouring over massive volumes of information and there's been nobody there to look at the patient and think about the meaning of the data you're actually analyzing. I think the risk of having associations that don't reflect causality is pretty high; I don't think we're going to be able to get away from the need to randomize patients to establish causal relationships.

Blanch: I think both are very important for the future.

\section{REFERENCES}

1. Pham T, Telias I, Piraino T, Yoshida T, Brochard LJ. Asynchrony consequences and management. Crit Care Clin 2018;34(3):325341.

2. de Haro C, Magrans R, López-Aguilar J, Montanyà $\mathrm{J}$, Lena $\mathrm{E}$, Subirà $\mathrm{C}$, et al. Effects of sedatives and opioids on trigger and cycling asynchronies throughout mechanical ventilation: an observational study in a large dataset from critically ill patients. Crit Care 2019;23(1):245.
3. Marchuk Y, Magrans R, Sales B, Montanya $\mathrm{J}$, López-Aguilar $\mathrm{J}$, de Haro $\mathrm{C}$, et al. Predicting patient-ventilator asynchronies with hidden Markov models. Sci Rep 2018;8 (1): 17614

4. Thille AW, Rodriguez P, Cabello B, Lellouche F, Brochard L. Patient-ventilator asynchrony during assisted mechanical ventilation. Intensive Care Med 2006;32 (10): 1515-1522.

5. Vaporidi K, Babalis D, Chytas A, Lilitsis E, Kondili E, Amargianitakis V, et al. Clusters of ineffective efforts during mechanical ventilation: impact on outcome. Intensive Care Med 2017;43(2): 184-191.

6. Rué M, Andrinopoulou ER, Alvares D, Armero C, Forte A, Blanch L. Bayesian joint modeling of bivariate longitudinal and competing risks data: An application to study patient-ventilator asynchronies in critical care patients. Biom J 2017;59(6):1184-1203. 